CUAD. CONTAB. / BOGOTÁ, COLOMBIA, 17 (43): 203-254 / ENERO-JUNIO 2016 / 203

\title{
Gobierno corporativo y desempeño financiero: conceptos teóricos y evidencia empírica*
}

doi:10.11144/Javeriana.cc17-43.gcdf

\section{Natalia Escobar-Váquiro}

Estudiante de doctorado en ciencias sociales, Facultad Latinoamericana de Ciencias Sociales, FLACSO. Magíster en economía aplicada, Universidad del Valle. Contadora pública, Pontificia Universidad Javeriana. Becaria, Consejo Nacional de Investigaciones Científicas y Técnicas, CONICET. Integrante del grupo de investigación Inversión, Financiación y Control, Universidad Icesi. Integrante del Instituto de Estudios Laborales y del Desarrollo Económico, IELDE, Universidad Nacional de Salta.

Correo electrónico: nataliaescobar@javerianacali.edu.co

\section{Julián Benavides-Franco}

Doctor en finanzas, Universidad de Tulane. Maestría en administración, Universidad de Tulane. Maestría en finanzas, Universidad Icesi. Maestría en administración, Universidad Icesi. Ingeniero eléctrico, Universidad de los Andes. Actualmente, se desempeña como director del departamento de estudios contables y financieros, director del grupo de investigación Inversión, Financiación y Control y profesor tiempo completo, Universidad Icesi.

Correo electrónico: jbenavid@icesi.edu.co

\section{Héctor Fabio Perafán-Peña}

Estudiante de doctorado en contabilidad y finanzas corporativas, Universidad de Valencia. Magíster en finanzas, Universidad Icesi. Contador público, Universidad Icesi. Economista, Universidad Icesi. Integrante del grupo de investigación Inversión, Financiación y Control, Universidad Icesi. Actualmente, se desempeña como profesor tiempo completo, Universidad Icesi.

Correo electrónico: hfperafan@icesi.edu.co

\footnotetext{
* Este es un artículo de revisión desarrollado en el marco del proyecto de investigación: El gobierno corporativo y su papel en el desempeño financiero de las fusiones y adquisiciones. Dicho proyecto se llevo a cabo bajo un convenio interadministrativo entre la Universidad Icesi y la Superintendecia de sociedades. Además, esta investigación hace parte de los resultados de investigación de la pasantía de jóvenes investigadores de Colciencias 617 de la que hicieron parte dos de los autores de este documento.
} 
Resumen Este documento tiene como objetivo la estructuración de un marco de análisis para el estudio de prácticas de gobierno corporativo y su incidencia en los resultados financieros, teniendo en cuenta estudios teóricos y empíricos en países desarrollados y en desarrollo, principalmente latinoamericanos, con énfasis en Colombia. Las prácticas de gobierno corporativo se han convertido en un elemento esencial de los estudios de la teoría de la firma en vista de que proveen a los gestores y propietarios de mecanismos que permiten establecer normas encaminadas a la minimización de conflictos de interés, la consecuente mejora y transparencia en la toma de decisiones y, por ende, elevar los niveles de desempeño financiero. A partir de la metodología de análisis documental propuesta por David Papineau, se encuentran una significativa evolución y convergencia en la normativa internacional y nacional en lo relacionado con prácticas de gobierno corporativo y su relación con el desempeño; resalta el incipiente impacto en Colombia y otros países en desarrollo. Entre los resultados más relevantes están la necesidad de abordar las prácticas de gobierno corporativo y su impacto sobre los retornos financieros de las firmas desde un enfoque multiteórico, al igual que la identificación del problema que para las investigaciones empíricas representa la endogeneidad entre el desempeño financiero y el gobierno corporativo.

Palabras clave Gobierno corporativo; desempeño financiero; teoría de la agencia; teoría del servidor o stewardship; Latinoamérica; Colombia

\section{Clasificación JEL G34, M14}

\section{Corporate Governance and Financial Performance: Theoretical Concepts and Empirical Evidence}

Abstract The purpose of this document is to structure an analysis framework for the study of the corporate governance practices and their effect on the financial results, taking into account theoretical and empirical studies in developed and developing countries, mainly in Latin America, with a particular emphasis in Colombia. Corporate governance practices have become an essential element in the theory of the firm studies, since they provide managers and owners with mechanisms that allow for the establishment of regulations aimed at minimizing conflicts of interests, with the resulting improvement and transparency in decision making and, thus, increasing the financial performance levels. Based on the documental analysis methodology proposed by David Papineau, we found a significant evolution and convergence in terms of national and international regulations related with corporate governance practices and their relationship with performance, with a highlight on its emerging effect in Colombia and in other developing countries. Among the most relevant results we found the need to address the corporate governance practices and their impact on the financial returns of firms from a multi-theoretical approach, and also to identify the problem caused by endogeneity between financial performance and corporate governance for empirical research.

Keywords Corporate governance; financial performance; agency theory; stewardship theory; Latin America; Colombia

\section{Governança corporativa e desempenho financeiro: conceitos teóricos e evidencia empírica}

Resumo Este documento tem como objetivo a estruturação de um quadro de análise para o estudo de práticas de governança corporativa e a sua incidência nos resultados financeiros, levando em conta estudos teóricos e empíricos em países desenvolvidos e em desenvolvimento, principalmente latino-americanos, com ênfase na Colômbia. As práticas de governança corporativa tornaram-se elemento essencial dos estudos da teoria da firma em vista a que fornecem mecanismos para gestores e proprietários per- 
GOBIERNO CORPORATIVO Y DESEMPEÑO FINANCIERO / N. ESCOBAR, J. BENAVIDES, H. PERAFÁN / 205

mitindo estabelecer normas encaminhadas à minimização de conflitos de interesse, o consequente melhoramento e transparência na tomada de decisões e, por tanto, elevar os níveis de desempenho financeiro. A partir da metodologia de análise documental proposta por David Papineau, encontra-se uma significativa evolução e convergência na normativa internacional e nacional no relacionado com práticas de governança corporativa e seu relacionamento com o desempenho; remarca-se o incipiente impacto na Colômbia e outros países em desenvolvimento. Entre os resultados mais relevantes está a necessidade de abordar as práticas de governança corporativa e seu impacto sobre os retornos sobre investimento das firmas desde um enfoque multiteórico, bem como a identificação do problema que para as pesquisas empíricas representa a endogeneidade entre o desempenho financeiro e a governança corporativa.

Palavras-chave Governança corporativa; desempenho financeiro; teoria da agência; teoria do servidor o stewardship; Latino-américa; Colômbia

\section{Introducción}

Este estudio intenta aportar a la comprensión de la problemática de gobierno corporativo (en adelante, GC) de las organizaciones desde varias perspectivas. Primero, construye un marco conceptual, que posibilita la discusión del GC y su evolución reciente; segundo, aborda la revisión de estudios empíricos relevantes; y tercero, discute algunas de las dificultades empíricas con las que tratan estos estudios. En los estudios interdisciplinarios del capitalismo (Boyer, 2007), esta revisión de la literatura, enmarcada en el método de investigación de la economía financiera y las teorías asociadas con el GC, contribuye a la comprensión de sus efectos en el desempeño de las firmas alrededor del mundo, en particular para América Latina y Colombia. Este estudio también documenta la proliferación de guías y códigos de gobierno alrededor del mundo, bajo la premisa de la maximización de valor para el accionista, comenta la racionalidad de esta convergencia normativa y expone algunos argumentos en su contra. Además, cimienta los esfuerzos que deben realizarse para evaluar la efectividad de las reformas y recomendaciones sobre GC, su creciente momentum y la homogeneidad que predican.

A lo largo del tiempo, las personas han buscado formas productivas de organizarse para satisfacer necesidades y esto ha dado origen a las organizaciones; las primeras menciones acerca de estas las hacen filósofos desde los 500 a.C. como Sócrates, Platón, Aristóteles o en la Edad Media, Erasmo de Rotterdam, entre otros (Fernández-Aguado, 2006). Sin embargo, el concepto de empresa moderna, en el contexto de este artículo - las sociedades por acciones - nace de la mano del desarrollo de los países europeos y sus colonias. A mediados del siglo XVI, se fundó la Company of Merchant Adventurers to New Lands, con 250 accionistas en el Reino Unido. En 1600, nació en Londres la East India Company, a la cual se le garantizó el monopolio de las operaciones comerciales con la India Oriental por 15 años. En 1602, en Amsterdam, se creó la Dutch East India Company (Vereenigde Oost-Indische Compagnie, VOC) la primera empresa en listar sus acciones en bolsa.

Estas organizaciones se han desarrollado de manera análoga con la sociedad y han tomado un papel preponderante dentro de ella. La premisa fundamental de la importancia 
de la empresa dentro de la sociedad surge del interrogante ¿Por qué existen las firmas? El primero en avanzar en esta cuestión fue el economista y abogado británico Ronald H. Coase en 1937; a partir de su teoría de la firma, diversos autores han discutido y ampliado los argumentos. Básicamente, la premisa del porqué de la existencia de la firma gira en torno a la disminución de dos tipos de costos: los costos de coordinación que se logra al organizar actividades dentro de las empresas y los de transacción al reducir importes dentro de los mercados (Tarziján, 2003).

Así mismo, en los estudios sociales, la temática organizacional se enfoca en analizar su estructura, los mecanismos para lograr su eficiencia y sus implicaciones para la sociedad en su conjunto. Con lo anterior, a partir del concepto de organización, y teniendo en cuenta los cambios políticos, económicos y sociales desde la época del mercantilismo en el siglo XVII, pasando por la aparición de las empresas industriales en el capitalismo industrial del siglo XIX y transitando por el capitalismo financiero y la importancia del capital como principal factor de producción, surge la empresa moderna.

Así pues, según Markus Kallifatides, Sophie Nachemson-Ekwall y Sven-Erik Sjöstrand (2010), el capitalismo financiero es resultado de las condiciones de financiarización de los mercados que conlleva el incremento de las motivaciones financieras, mercados financieros, actores financieros e instituciones financieras en las operaciones de toda la economía. Estos cambios se han presentado a gran escala desde la década de los 80 y han puesto en marcha una nueva forma de hacer negocios, caracterizada principalmente por una fuerte expansión del crédito; tasas de interés volátiles; altos volúmenes de transacciones de instrumentos financieros; incremento en los empleos asociados al sector financiero e ingresos asociados a él; extremas fluctuaciones en el valor de los activos y aumentos en sus garantías de los mismos, debido a las especulaciones; además de un considerable incremento en riesgos de decisiones adversas y riesgo moral. Todo esto repercute de manera directa en las decisiones de toda la economía, tanto del sector real como del financiero.

De este modo, se refuerza la necesidad de gobernar la empresa de manera eficiente para cumplir los objetivos organizacionales y dar origen a las ideas que en forma genérica se conocen como GC, al refinar conceptos sobre control, enunciados (Smith, [1776] 1994) o abordados en las primeras etapas de los estudios organizacionales (Berle \& Means, [1932] 1991). Estos objetivos organizaciones, en este contexto, se vinculan con el desempeño financiero. ${ }^{1}$ Por esto, es común que los investigadores usen como hipótesis central que a mejores prácticas de gobierno corporativo se obtengan mejores resultados en los indicadores de desempeño financiero.

En términos generales, desde la perspectiva de la teoría de la agencia, las prácticas de GC

1 Es común en la literatura asociar el desempeño financiero con resultados en los indicadores financieros como ROA (Retorno sobre los activos), Q de Tobin (el cociente entre el valor de mercado de la firma y su costo en libros o de reposición. Un mayor valor se asocia a un mejor desempeño), crecimiento de las ventas, índice de apalancamiento, entre otros. Ver sección Gobierno corporativo. 
buscan proteger los intereses de los propietarios de la firma (estos intereses se relacionan directamente con el desempeño financiero), es decir, los dueños del capital financiero pueden verse afectados por el gestor de la firma (este concepto se amplía en secciones posteriores). Desde esta óptica, el GC protege el capital del accionista y maximiza sus retornos, por lo cual se torna fundamental en la práctica organizacional. Enfoques alternativos (Aglietta \& Rebérioux, 2005) disputan el objetivo de maximización, por lo que el GC se debería centrar en garantizar unas relaciones fluidas en los grupos de interés, que consensuadamente definen el objetivo empresarial.

Con este panorama, esta investigación busca desarrollar un análisis documental de los estudios teóricos y empíricos que permiten obtener un marco de análisis para el estudio de las prácticas de GC y su incidencia sobre el desempeño financiero, con énfasis en el contexto colombiano. Es importante mencionar que este recorrido se hace desde la óptica del problema de agencia que será ampliado en este documento.

En este sentido, la elaboración de estados del arte o estados de la cuestión es un elemento fundamental para el reconocimiento de la evolución de la ciencia y para la construcción de una comunidad académica alrededor de una temática (Grajales-Quintero, Cuevas-Mejía \& Usme-Suárez, 2013). Así mismo, componer este tipo de documentos enriquece el marco de análisis con el cual se aborda una temática, sobre todo en países emergentes en los que la literatura es escasa y la investigación empresarial se dificulta por diversas razones, como fal- ta de datos o la renuencia de los empresarios o propietarios de la firma a permitir el acceso a la información relacionada con sus prácticas empresariales; primero, porque los administradores tienden a revelar información de manera selectiva de tal forma que no los afecte $y$, segundo, porque no hay un desarrollo concreto del modelo de información financiera asociado a la práctica de divulgación de la información (Sunder, 1997).

El documento se estructura iniciando con esta introducción, seguido de la explicación del método de investigación; en el aparte siguiente, se configura el marco teórico sobre el que gira esta investigación; a continuación, se elabora el recorrido por el estado de la cuestión de la temática; se finaliza con unas breves conclusiones.

\section{Metodología}

Esta investigación se realizó por medio del análisis documental. Se dio inicio con el análisis de los artículos seminales sobre la teoría de agencia y la teoría del servidor (stewardship) que son la base para el desarrollo del concepto de GC. A continuación, se desarrolla el concepto de GC. Acto seguido, se lleva a cabo la búsqueda de los artículos empíricos que se han desarrollado a partir del estudio de los avances de las prácticas de GC y su relación con el desempeño financiero de las firmas. Adicionalmente, estas temáticas se estudian en el contexto latinoamericano y colombiano. Finalmente, se hace un breve análisis del problema más común en el tratamiento de datos de GC y de los retornos financieros. 
El método de revisión de los documentos usado es el propuesto por David Papineau (1979), que consiste en ordenar de manera descendente los términos, separando los princi- pales para la comunidad en general hasta llegar a los que son compartidos por un grupo de especialistas (gráfica 1) (Ryan, Scapens \& Theobald, 2004).

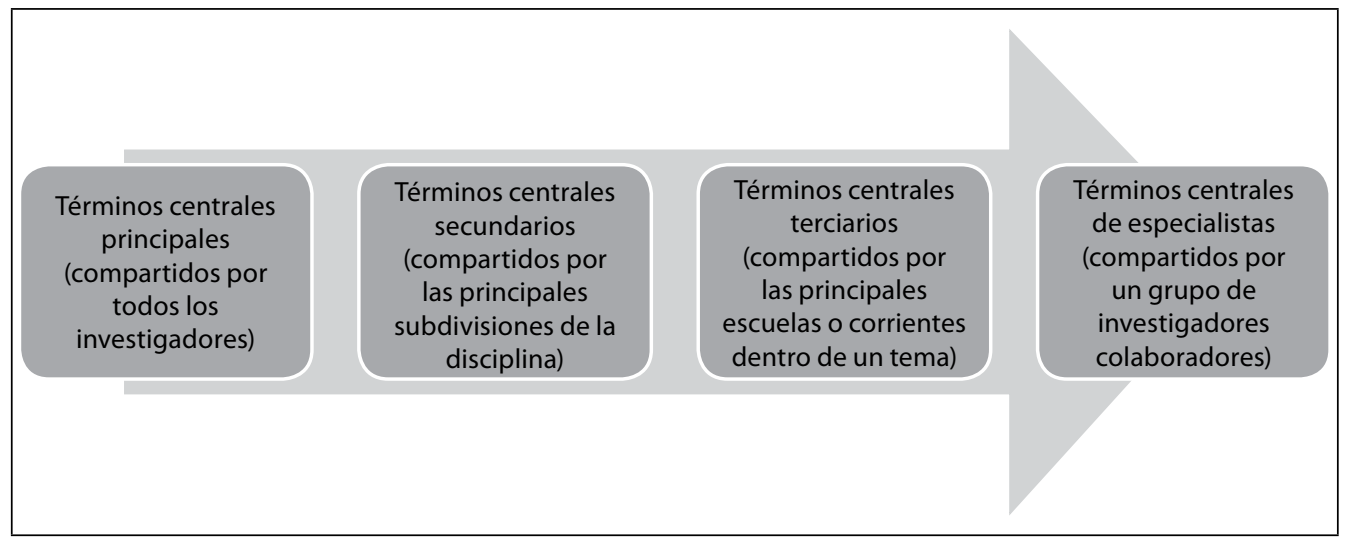

Gráfica 1

Árbol de Papineau

Fuente: elaboración propia con base en Bob Ryan, Robert W. Scapens y Michael Theobald (2004)

A partir de este diagrama, se elaboró una clasificación de los documentos a estudiar que se observa en la gráfica 2. En el primer elemento de términos centrales principales están los fundamentos teóricos que sustentan las prácticas de GC (teoría de la agencia y teoría del stewardship). En el segundo componente que contiene los términos centrales secundarios se ubica el desarrollo teórico de las prácticas de GC. El tercer factor agrupa los desarrollos empíricos relacionados con las prácticas de GC. La categoría de país desarrollado corresponde al MSCI ACWI \& Frontier Market Index (Morgan Stanley Capital International, MSCI, s.f.) que define los mercados desarrollados ${ }^{2}$ y los

2 Los países desarrollados son: i) en América: Canadá y Estados Unidos; ii) En Europa y Oriente Medio: Alemania, Austria, Bélgica, Dinamarca, España, Finlandia, Francia, países emergentes. Entre los países emergentes se hace énfasis en los desarrollos empíricos en América Latina, en especial Colombia.

En el elemento final que contiene los términos centrales especialistas hay una revisión del tratamiento de los datos, a partir de la relación entre las prácticas de GC y el desempeño financiero (gráfica 2).

Irlanda, Israel, Italia, Países Bajos, Noruega, Portugal, Reino Unido, Suecia, Suiza; y finalmente iii) en el Pacífico: Australia, Hong Kong, Japón, Nueva Zelanda, Singapur. Fuente: Morgan Stanley Capital International, MSCI (s.f.). All Country World Index \& Frontier Market Index, MSCI ACWI $\&$ Frontier Index. Disponible en: https://www.msci.com/ indexes 
GOBIERNO CORPORATIVO Y DESEMPEÑO FINANCIERO / N. ESCOBAR, J. BENAVIDES, H. PERAFÁN / 209

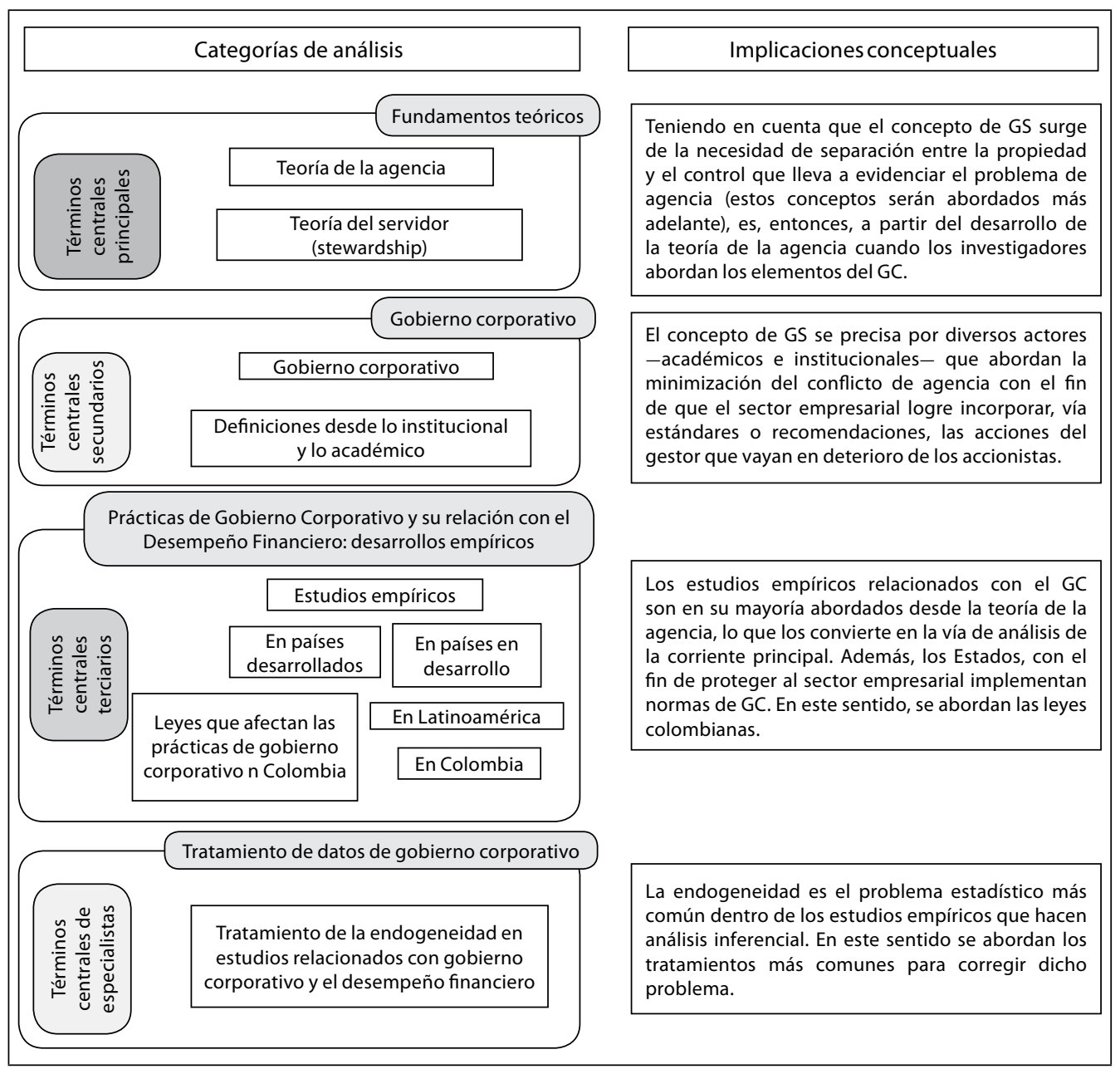

Gráfica 2

Clasificación de documentos, a partir de la metodología de árbol de Papineau

Fuente: elaboración propia con base en Bob Ryan, Robert W. Scapens y Michael Theobald (2004)

\section{Ejes teóricos}

\subsection{Teoría de la agencia}

De acuerdo con Eugene Fama y Michael C. Jensen (1983), la organización es un conjunto de contratos o reglas internas escritas o no escritas que especifican las etapas del proceso de toma de decisiones dentro de la organización, la co- rrespondencia, los derechos residuales ${ }^{3}$ y los mecanismos de control de la separación entre propiedad y control. Estos mecanismos emergen a partir de los procesos de decisión y el perfil de las contrapartes involucradas. Estas reglas definen los derechos de cada contraparte dentro de

3 Los derechos de tomar decisiones en el caso de eventos no contemplados por los contratos. 
la organización, los criterios de evaluación y la función de pagos de cada uno. A su vez, la estructura de contratos se combina con la capacidad tecnológica de producción y los contratos externos para determinar la función del costo. Con estas mismas premisas funcionan las empresas con la diferencia de que estos contratos distinguen entre los propietarios de los factores de producción, los agentes a cargo de la producción y los clientes ${ }^{4}$. Así, mientras una firma proporcione un producto demandado a los más bajos precios y cubra sus costos (incluyendo la utilidad esperada por sus propietarios), sobrevivirá.

Adicionalmente, estos contratos especifican la naturaleza de los derechos residuales y el fraccionamiento de los procesos de decisión entre las contrapartes. Los derechos residuales se asocian con la contraparte que asume el riesgo residual ${ }^{5}$. Estos individuos, en contraprestación por el riesgo asumido, obtienen los derechos sobre los flujos de efectivo y son llamados portadores de riesgo residual. Además, reducen su riesgo asumiendo costos de monitoreo o diversificando sus derechos de propiedad con otros individuos. Por otro lado, el fraccionamiento de los procesos de decisión busca controlar el poder que se le otorga al gestor de la organización. Es decir, el gestor debe seguir algunos lineamientos que no le permitirán tomar decisiones con la totalidad de los recursos de la empresa. Algunos de estos protocolos incluyen un monto límite en el

4 En este caso, las empresas se consideran como un tipo de organización con ánimo de lucro que, a partir de la realización de actividades productivas, buscan ofrecer un bien o servicio a cambio de beneficios económicos.

5 Diferencia entre las entradas estocásticas de recursos y los pagos fijos prometidos a los agentes. que se pueden hacer operaciones o procesos de supervisión mediante auditorías independientes que no son controladas por el gestor. Estas diferentes prácticas que buscan la reducción de riesgos para los proveedores de capital se conocen como prácticas de GC.

Es decir, la necesidad del GC nace del supuesto de la separación de la propiedad y el control. A su vez, se evidencia la naturaleza del problema de agencia y cómo los contratos con incentivos apropiados pueden ser una solución a este problema. Andrei Shleifer y Robert W. Vishny (1997) describen el problema en mención (agencia) de la siguiente forma: un gestor de recursos, que bien puede ser un empresario o un gerente, recauda fondos de inversionistas, dado que no tiene capital propio suficiente o quiere retirar parcial o totalmente su participación de la firma. Estos inversionistas suministran el capital con la finalidad de obtener beneficios $y$, a su vez, necesitan los conocimientos especializados del gestor para producir retornos de su inversión. No obstante, los inversionistas no tienen la certeza de que el gestor de sus fondos les dé el uso adecuado o en el peor de los casos, decida apropiarse de ellos (riesgo moral - ex post-, debido a las limitaciones de monitoreo). En esta incertidumbre (conflicto de intereses), surge el problema de agencia. Por otra parte, la asimetría de información que caracteriza los procesos de asignación de recursos entre el gestor/propietario y los proveedores de capital puede generar fenómenos de selección adversa (ex ante), cuando solo los prospectos más riesgosos acceden a las demandas del proveedor de capital. 
En este sentido, según Michael C. Jensen y William H. Meckling (1976), ambas partes (principal y agente) son maximizadoras de sus beneficios; dado esto, el agente siempre buscará mejorar el beneficio del principal siempre y cuando esto maximice su propio beneficio. Por esto, el principal establece incentivos que permitan limitar algunas acciones del gestor que vayan en detrimento de su beneficio. Adicionalmente, estos individuos asumen costos adicionales en este contrato, que son denominados costos de agencia. Estos costos son: i) gastos de supervisión del principal, como auditorías internas o externas y revisoría fiscal, ii) gastos de garantía del agente; que son incentivos económicos (bonificaciones o acciones de la compañía) que se le otorgan al gestor, a partir del desempeño financiero de la organización con el fin de que sus intereses se alineen con los de los propietarios y iii) una pérdida residual, que se refiere a la pérdida de bienestar que experimenta el principal causada por las divergencias entre las decisiones que toma el agente y las acciones que maximizan su propio bienestar.

Estos mismos autores sugieren que cuando una empresa es gestionada por su propietario, sus decisiones irán encaminadas a maximizar su utilidad. Esta utilidad contiene beneficios tanto pecuniarios como no pecuniarios (la cantidad y el tipo de donaciones, las relaciones personales, la compra de insumos para mejorar relaciones con sus amigos). Si el propietario decide vender una parte de la firma, los costos de agencia se generan de la divergencia que hay entre el interés del propietario y los accionistas externos a la compañía. Así que el propietario continuará gastando recursos para maximizar su propia utilidad; por tanto, los accionistas externos deben asumir costos de monitoreo del gestor-propietario para disminuir la divergencia; con esto, esos accionistas potenciales descontarán estos costos del valor que tendrían las acciones de no existir esta divergencia. El propietario (gestor) original optará por asumir este descuento siempre y cuando el incremento de bienestar que experimente sea suficiente como para compensar los costos.

De otra parte, Eugene Fama y Michael C. Jensen (1983) argumentan que el problema de agencia se genera dado que no hay claridad en los costos producidos por el efecto de la separación entre propiedad y control; es decir, en la estructura de los costos, monitoreo y unificación de una serie de contratos entre agentes con conflictos de interés. Además, los costos de agencia incluyen el valor que se puede perder cuando los contratos intentan incluir los costos de agencia en su totalidad $y$, a su vez, esta pérdida puede llegar a exceder los beneficios.

La dicotomía entre propiedad y control puede ser total, con lo cual el control en las decisiones de gestión se convierte en un elemento fundamental en la medida en que los responsables de la gestión no son los poseedores de los derechos residuales (propietarios) ${ }^{6}$ y por tanto, no perciben los efectos de la riqueza a partir de sus decisiones. Eugene Fama y Michael C. Jensen (1983), en una reflexión sobre la toma de decisiones y esquemas organizacionales,

6 Las personas que contraen los derechos de los flujos de caja y por tanto, asumen los riesgos residuales. Adolf A. Berle y Gardiner C. Means (1932) en su libro The Modern Corporation and Private Property documentan y estudian este fenómeno. Adam Smith (1776) lo anticipa en su libro seminal La riqueza de las naciones. 
consideran que la concentración de ambos tipos de decisión (gestión y control) y la tolerancia al riesgo residual en pocos agentes son una buena alternativa para empresas no complejas ${ }^{7}$ en las que los gestores son además los propietarios de las firmas. Sin embargo, esta solución de concentración tiene el inconveniente de una diversificación del riesgo subóptima, que puede reducirse en la medida en que el crecimiento de la empresa posibilite la desinversión con propósitos de liquidez y diversificación.

En adición a lo planteado, Eugene Fama y Michael C. Jensen (1983) estudian el papel que cumplen los conocimientos específicos. En este sentido, la información específica y valiosa para las decisiones suele difundirse entre muchos individuos y niveles dentro de la organización. Por esto, mejores beneficios se logran al delegar funciones de decisión entre diversos agentes con conocimientos específicos relevantes en todos los niveles de la organización. Por otro lado, el rol de la difusión de los derechos residuales es trascendental dado que su separación y difusión permite controlar los problemas de agencia mientras esta limita el poder de los agentes individuales para tomar ventaja de los demandantes residuales ${ }^{8}$; esto permite una mayor supervivencia de las organizaciones complejas. Por último, estos autores plantean que las organizaciones en general tienen características comunes en los sistemas de control de las decisiones, es decir, su separación de la propiedad y el control es similar.

7 Los autores definen no complejidad como la concentración de las decisiones en uno o unos pocos agentes. 8 Andrei Shleifer y Robert W. Vishny (1997) asocian la concentración de la propiedad con la debilidad regulatoria. Esta hipótesis fue desarrollada en diferentes artículos que se analizan más adelante.
Hay diversos incentivos para prevenir las conductas asociadas al problema de agencia. Jean Tirole (2005) los clasifica entre monetarios y no monetarios. Los primeros se refieren a paquetes de compensación, bonos y acciones, y en general a los recursos que aumentan la riqueza del gestor. Los no monetarios son incentivos implícitos como la preocupación del gerente por mantenerse en su cargo o su temor a la bancarrota. Todos estos procesos son vigilados por la junta directiva9 ${ }^{9}$ Así, los procesos que la junta directiva lleva a cabo son de suma importancia para mitigar las actuaciones en contra de los intereses de los accionistas.

$\mathrm{Al}$ respecto, Andrei Shleifer y Robert W. Vishny (1997) exponen como mecanismos alternativos de gobernanza lo siguientes elementos. i) La reputación que es un mecanismo relevante dentro del mundo empresarial, pues los gerentes se ven obligados a cumplir sus promesas para mantener su reputación y los inversionistas suministran recursos a partir de la misma. Los gerentes necesitan acreditar que su gestión presenta un bajo riesgo con el fin de persuadir a futuros inversores de entregarles su dinero. A pesar de que la reputación es trascendental para los inversionistas, estos modelos presentan problemas y por tanto, no son capaces de explicar en su totalidad la financiación de las firmas. Un claro ejemplo de esto son los esquemas Ponzi (pirámides que reciben ese

9 La junta directiva surge esencialmente como un subproducto de la regulación necesaria dentro de las firmas (Hermalin \& Weisbach, 2003). La calidad de la regulación dependerá de su independencia; esta independencia se refleja en la forma en la que la junta contrata, promueve, evalúa y despide al gerente o influye en esas decisiones (Adams, Hermalin \& Weisbach, 2010). 
GOBIERNO CORPORATIVO Y DESEMPEÑo FINANCIERO / N. ESCOBAR, J. BENAVIDES, H. PERAFÁN / 213

nombre por el estafador italiano Carlo Ponzi), que están sustentados simplemente en la reputación y el optimismo que los inversionistas tienen respecto a la firma. ii) En esta situación, entra a jugar un papel fundamental la protección legal que tienen los inversionistas respecto a los activos que conforman la empresa a la que suministraron sus recursos. Con esto, los inversionistas reciben derechos de control a cambio de sus recursos. En los casos en los que se deben tomar decisiones significativas dentro de una organización, los grandes accionistas tienen voz y voto; por ejemplo, en temas relacionados con la diversificación corporativa. No obstante, los derechos de voto deben estar combinados con la lealtad (o deber fiduciario) que deben tener los directivos con los accionistas, es decir, los gestores deben estar alineados con los intereses de los inversionistas. Así pues, en ciertos países, la legislación y su aplicación aseguran mejores condiciones respecto a los derechos de los accionistas. iii) Finalmente, la gobernanza puede asociarse con la concentración de la tenencia de acciones; con esto, los grandes accionistas aseguran el control de las firmas a partir de su poder de voto, y del grado con que la ley defienda sus derechos.

\subsection{Teoría del servidor - Stewardship}

Una alternativa a la teoría de agencia es la teoría del stewardship o del servidor ${ }^{10}$. Partiendo del hecho de que en la teoría de la agencia el agente está motivado exclusivamente por razones económicas y tiene un comportamiento

10 Esta traducción es tomada de Alfonso Vargas-Sánchez, Elena García de Soto-Camacho y María Jesús Moreno-Domínguez (2003). oportunista, surge esta teoría que busca tener una mirada más sociológica y psicológica de este individuo, en la que el agente es confiable pues basa su toma de decisiones en los intereses de la compañía a la que sirve, en vista de que está comprometido con el éxito de esta (Davis, Schoorman \& Donaldson, 1997; Donaldson, 1990; Donaldson \& Davis, 1991; Hassan, Marimuthu \& Johl, 2015).

Así, los intereses de los administradores y de los accionistas de las empresas están alineados, en vista de que los administradores son confiables, les preocupa su reputación y su utilidad se maximiza al actuar en beneficio de las organizaciones; estos hechos les impiden ir en contravía de los intereses de los accionistas (Nicholson \& Kiel, 2007; Tosi, Brownlee, Silva \& Katz, 2003; Wasserman, 2006). Incluso, si se presentara el caso en que los intereses de la organización chocan con los intereses del servidor, este último se inclina hacia los intereses de la organización (Tosi, Brownlee, Silva \& Katz, 2003). De esta forma, se espera que los administradores sean reacios a desperdiciar recursos de los accionistas pues están en pro de los intereses de la firma, por lo cual tratan de alcanzar cada vez mejores utilidades y retornos para los accionistas (Giovannini, 2010). De aquí que se argumente que los mecanismos de control delineados bajo la teoría de agencia pueden minar la motivación de la administración, entorpeciendo su papel en la organización, hecho que va en contravía de los intereses de los dueños (Lee \& O'Neill, 2003; Tosi, Brownlee, Silva \& Katz, 2003). Consecuentemente, algunas de las predicciones empíricas de la teoría de agencia son opuestas a esta teoría. En particular, la presencia de insiders en 
posiciones de control podría tener consecuencias positivas en el desempeño.

Así pues, este enfoque (servidor) no se centra en las motivaciones del administrador de los recursos, sino en las formas de facilitar y mejorar las estructuras de poder, lo cual asegura que el ambiente laboral del gestor lo incentive a adoptar un comportamiento en pro de la organización y favorecer que el gestor ostente el doble cargo de pertenecer a la junta directiva y ser el administrador, pues implicará mejoras en la efectividad y por tanto, mayores retornos para los accionistas (Donaldson, 1990; Donaldson \& Davis, 1991; Muth \& Donaldson, 1998). Esto se deriva del hecho de que los directores internos conocen más la empresa, en vista de que han trabajado mucho tiempo ahí y por ende, pueden tomar mejores decisiones en comparación con directores externos, hecho que lleva a que ante una mayor participación de la administración en el control de la empresa se experimente un mejor desempeño financiero (Nicholson \& Kiel, 2007). Referente a este punto, incluso si hubiera costos de agencia que hicieran que el monitoreo sea relevante, los directores independientes carecen del conocimiento necesario para hacer un monitoreo efectivo (Nicholson \& Kiel, 2007).

Otro tema importante para discutir es que si al dar este doble poder al gestor sus intereses realmente estarán alineados con los de los principales. A pesar de que no hay muchos estudios que intenten contrastar esta temática, Mark A. Fox y Robert T. Hamilton (1994) mediante el análisis de 97 diversificaciones corporativas ${ }^{11}$ en

11 Según Mark A. Fox y Robert T. Hamilton (1994), la diversificación corporativa es frecuentemente percibida como un mecanismo de búsqueda del beneficio propio del
Nueva Zelanda encuentran que la causa principal de estas actuaciones corporativas es tratar de hacer frente a problemas de rendimiento y no a los intereses propios de los gestores.

Aunque estas teorías se han presentado como contrarias, algunos autores plantean esta situación de manera diferente. Un documento más reciente Ralf Caers, Cindy du Bois, Marc Jegers, Sara de Gieter, Catherine Schepers y Roland Pepermans (2006) indica que el enfoque teórico del servidor es un caso de la teoría de la agencia en el cual todos los intereses logran estar alineados en algunos tipos de organizaciones especiales, como las cooperativas y organizaciones sin ánimo de lucro. Para entender mejor este punto, la gráfica 3 muestra una recta que representa el nivel de conflictos de agencia; este nivel aumenta a medida que la organización se ubica desde el enfoque de contratación óptima, es decir, los contratos establecen claras líneas que permiten hacer seguimiento y supervisión al gestor, lo que lleva a disminuir el poder de gestión que tendría este individuo; contrario al caso de una organización que establece el enfoque de poder gerencial, en el que al gestor se le faculta para tomar todas las decisiones de manera autónoma pues se parte del hecho de que este individuo toma las decisiones con base en los intereses de los accionistas. Es entonces en el punto cero en el que la organización se ubica solo desde el enfoque gerencial en el que se cumple la teoría del servidor como el caso límite de la teoría de la agencia.

gestor a expensas de los recursos a él entregados por los accionistas. Esto muestra que la teoría de la agencia tiene un fuerte impacto sobre las formas de gestión de las firmas y las creencias que se tienen acerca del comportamiento de los gestores. 


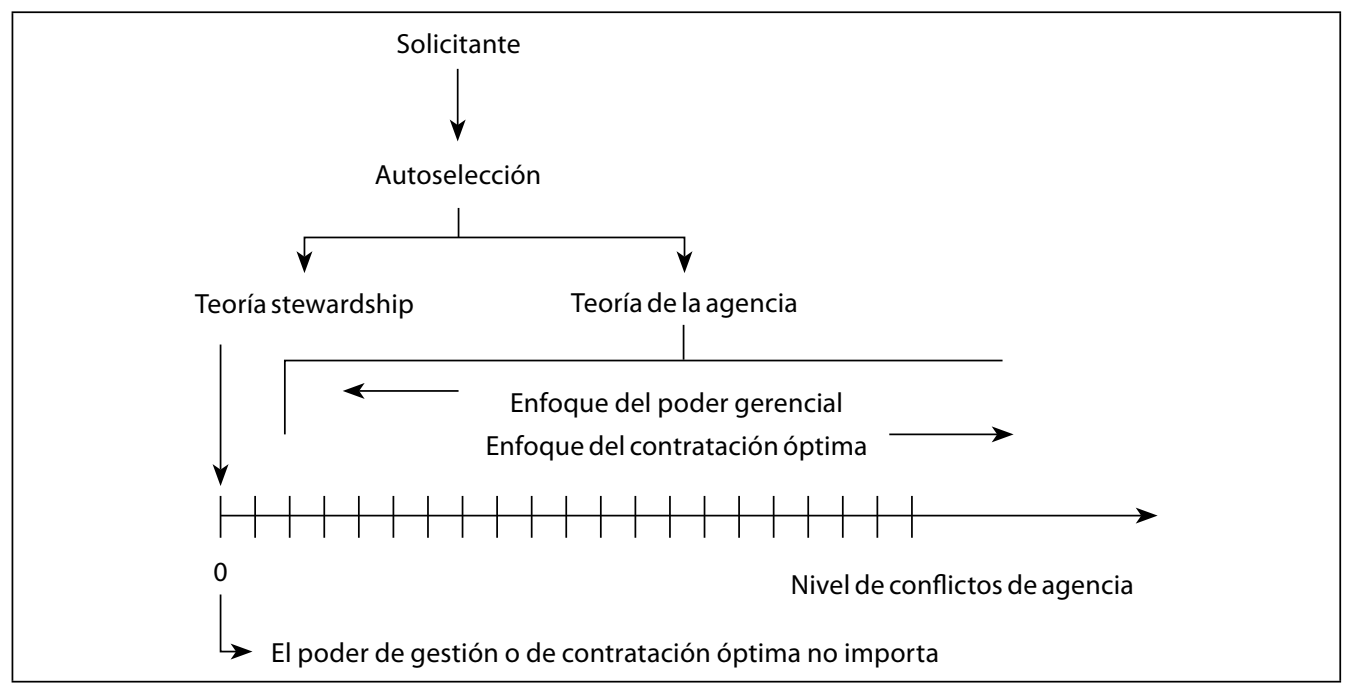

\section{Gráfica 3}

Posicionamiento de las teorías de la agencia y del servidor Fuente: tomado y traducido de Ralf Caers, Cindy du Bois, Marc Jegers, Sara de Gieter, Catherine Schepers y Roland Pepermans (2006)

Por otro lado, Gavin J. Nicholson y Geoffrey C. Kiel (2007) en un estudio sobre la relación entre los atributos de la junta directiva y el desempeño de la firma, encuentran que si bien la teoría de agencia y la del servidor pueden explicar casos particulares, ninguna de estas teorías puede explicar los patrones generales de las relaciones encontradas entre la junta y el desempeño de las firmas. En este mismo sentido, Noam Wasserman (2006) valida que las dos teorías mencionadas - más allá de presentar puntos de vista conflictivos-se pueden entender como complementarias a la hora de explicar la remuneración de los altos ejecutivos en 528 nuevas empresas estadounidenses. Por su parte, Youngok Kim y Fei Yi Gao (2013), al referirse a las empresas familiares en China, encuentran evidencia que soporta la teoría contingente, la cual indica que dependiendo de ciertos factores situacionales y psicológicos a los que se enfrenta una empresa, los administradores se pueden comportar como agentes o servidores (Davis, Schoorman \& Donaldson, 1997).

De esta forma, no necesariamente los puntos de vista planteados por las teorías abordadas están en polos opuestos y son irreconciliables. No obstante, este trabajo se centrará en la discusión de los efectos sobre el desempeño financiero que tienen mayores niveles de GC desde la óptica de la teoría de agencia, ello en vista de que la mayoría de las investigaciones en este ámbito aborda la discusión con los preceptos de esa teoría, como dan cuenta Jonas Gabrielsson y Morten Huse (2004) y Rohail Hassan, Maran Marimuthuy y Satirenjit Kaur Johl (2015) ${ }^{12}$.

12 Pese a esto, el lector interesado puede consultar referencias a favor de la teoría del stewardship en trabajos 
En el apartado a continuación se introduce el concepto de GC, a partir de las teorías anteriormente mencionadas y los desarrollos desde la academia y las instituciones que han contribuido al desarrollo de las prácticas de GC.

\section{Gobierno corporativo}

A partir de los conflictos de interés y de la necesidad de una estructura de control para una organización compleja (Fama \& Jensen, 1983), se desarrolla el actual concepto de GC. El costo de agencia entre propietarios y administradores, anticipado por Adam Smith (1776) en su libro seminal La riqueza de las naciones ${ }^{13}$, es central en el estudio de Adolf A. Berle y Gardiner C. Means ([1932] 1991) sobre la estructura de propiedad y el control de las grandes empresas estadounidenses de la época. Para Adolf A. Berle y Gardiner C. Means, el poder ascendente de la "administración" podía tener serias consecuencias en el carácter democrático de ese país. Formalizado el costo de agencia en el ámbito empresarial por Michael C. Jensen y William H. Meckling (1976), este fue el punto de partida para el gran volumen de literatura académica que estudia el GC. En el ámbito empresarial, el interés por el GC surge a raíz de la

como el de Henry L. Tosi, Amy L. Brownlee, Paula Silva y Jeffrey P. Katz (2003) y el de Renato Giovannini (2010).

13 "De los directores de tales compañías (por acciones), sin embargo, siendo los administradores del dinero de otros y no del suyo propio, no puede esperarse que ellos lo vigilen con la misma ansiosa diligencia con la cual los socios en una sociedad privada frecuentemente vigilan el suyo propio... Negligencia y profusión, por lo tanto, deben siempre prevalecer, más o menos, en la administración de los asuntos de una compañía como tal" (Smith, 1776, tomo 5 , capítulo 1 , artículo 1 ). publicación del Reporte Cadbury (Committee on the Financial Aspects of Corporate Governance \& Cadbury, 1992), como respuesta a diferentes quiebras empresariales de alto perfil, atribuidas a fallas de GC. El profundo impacto de este reporte puede evidenciarse en el sitio web del Instituto Europeo de Gobierno Corporativo (http://www.ecgi.org), el cual listaba, para septiembre de 2015 (tabla 1), 444 versiones de códigos de gobierno, recomendaciones y reportes desarrollados por 94 países y ocho entidades multilaterales desde 1992 (gráfica 4). El año 2010 fue el de mayor actividad en esta materia, pues se emitieron 41 códigos y recomendaciones para diferentes tipos de empresas alrededor del mundo. Los reportes incluyen guías para empresas que cotizan en bolsa (fundamentalmente), empresas cerradas, de familia, intermediarios financieros e incluso empresas estatales; y sobre características de los organismos y prácticas de control, como la junta directiva y directores, auditoría, e inversionistas institucionales.

\begin{tabular}{lcc}
\hline \multicolumn{1}{c}{ Región } & Países & Códigos \\
\hline África & 9 & 24 \\
Asia-Pacífico & 11 & 58 \\
Asia & 17 & 39 \\
Europa del Este & 26 & 56 \\
Norteamérica & 6 & 32 \\
Suramérica & 5 & 14 \\
Europa Occidental & 20 & 186 \\
Total países & 94 & 409 \\
Multilaterales & 8 & 35 \\
Total general & 102 & 444 \\
\hline
\end{tabular}

Tabla 1

Códigos de gobierno alrededor del mundo Fuente: elaboración propia con base en Instituto Europeo de Gobierno Corporativo 


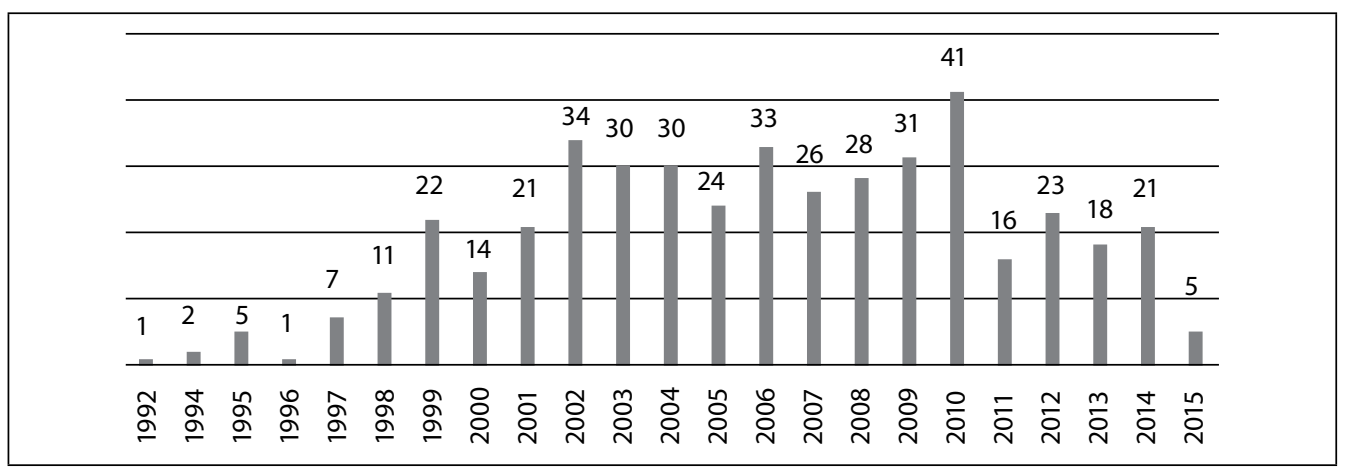

Gráfica 4

Códigos y reportes de GC emitidos en el mundo entre 1992 a 2015

Fuente: elaboración propia con base en el Instituto Europeo de Gobierno Corporativo

En la tabla 2 se presentan diferentes definiciones de GC. Aunque presentadas en línea temporal, y enfocadas fundamentalmente en empresas privadas, su variedad incorpora el enfoque del costo de agencia (Garay, González, González \& Hernández, 2006; Grant \& McGhee, 2014; Gruszczynski, 2006) más cercano a una visión financiera de la empresa y de su función social, dividiendo los actores involucrados entre accionistas y administradores; una aproximación más pluralista que incorpora diferentes clases de accionistas (Langebaek \& Ortiz, 2007; Love, 2011), hasta incorporar un sistema amplio que regula las relaciones entre gestores, y aquellos que invierten recursos (no necesariamente accionistas), considerando en este conjunto las leyes, regulaciones e instituciones que intervienen en estas relaciones (Lefort, 2003; Oman, Fries \& Buiter, 2003). Natalia Jara-Pinilla (2014) recoge a su vez estas diferentes ópticas en las definiciones que incorpora en su estudio.

De cierta manera, el concepto de GC ha evolucionado hasta considerarse como un sistema de normas y prácticas, formales e in- formales, externas e internas que regula las relaciones entre administradores y aquellos en beneficio de los cuales opera la organización. Esta definición incluyente incorpora otros tipos de organizaciones, como empresas sin ánimo de lucro y empresas asociativas, cuya estructura organizacional genera desafíos particulares respecto al GC y que se alejan del concepto básico del costo de agencia y se acercan a la visión pluralista de un administrador que responde a diferentes grupos de interés, no solo a los accionistas; además de considerar el rol de los reguladores, el imperio de la ley y las particularidades de la estructura de propiedad del entorno donde funcionan las organizaciones.

Con este panorama, las firmas han buscado y evolucionado a prácticas que permitan que los proveedores de capital disminuyan el riesgo que tienen frente a los gestores. No obstante, estas prácticas difieren según el contexto en que se encuentre la firma y no siempre son eficientes o eficaces; así se ha configurado toda una línea de investigación relacionada con las prácticas de GC y las implicaciones en su entorno. 


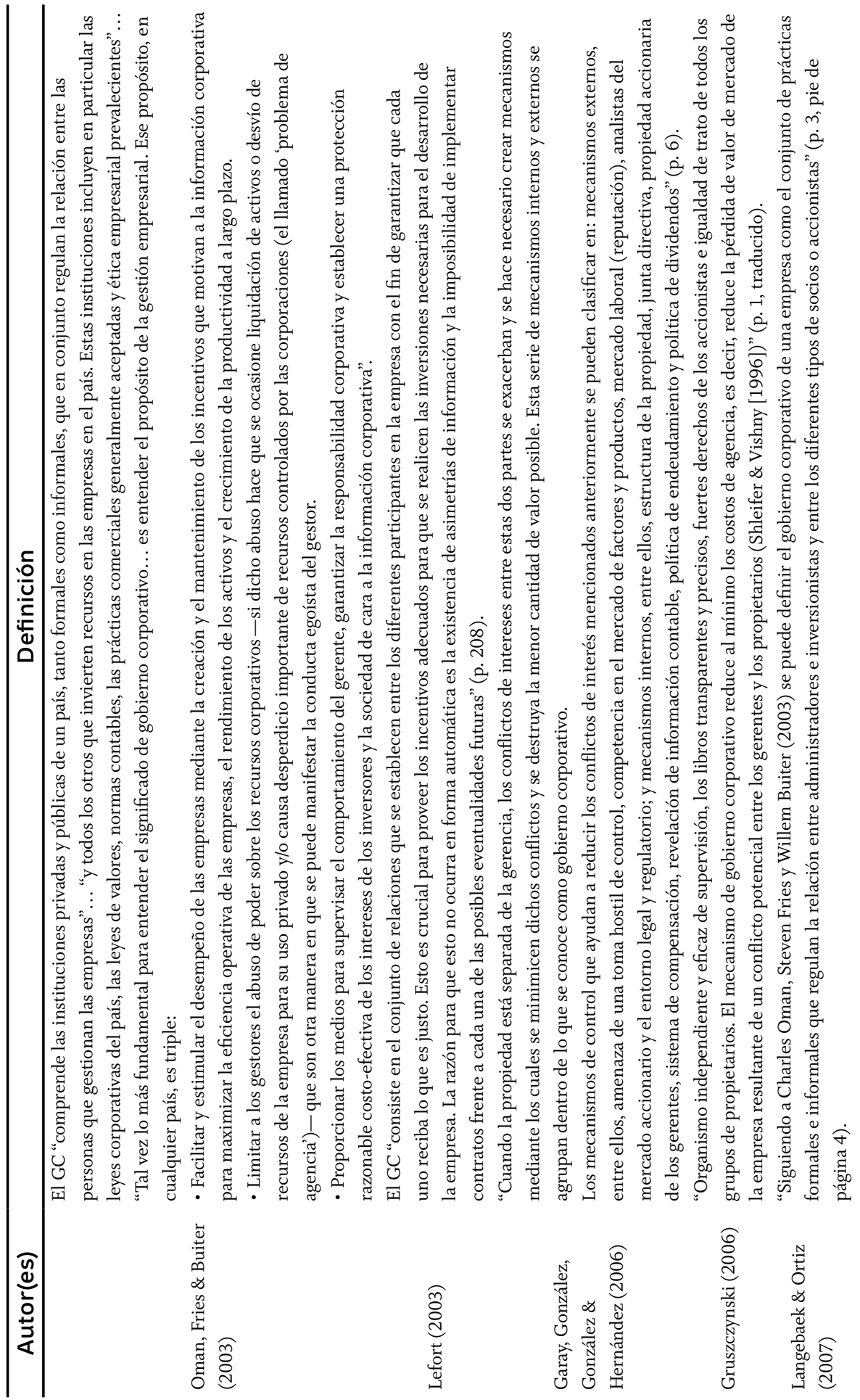




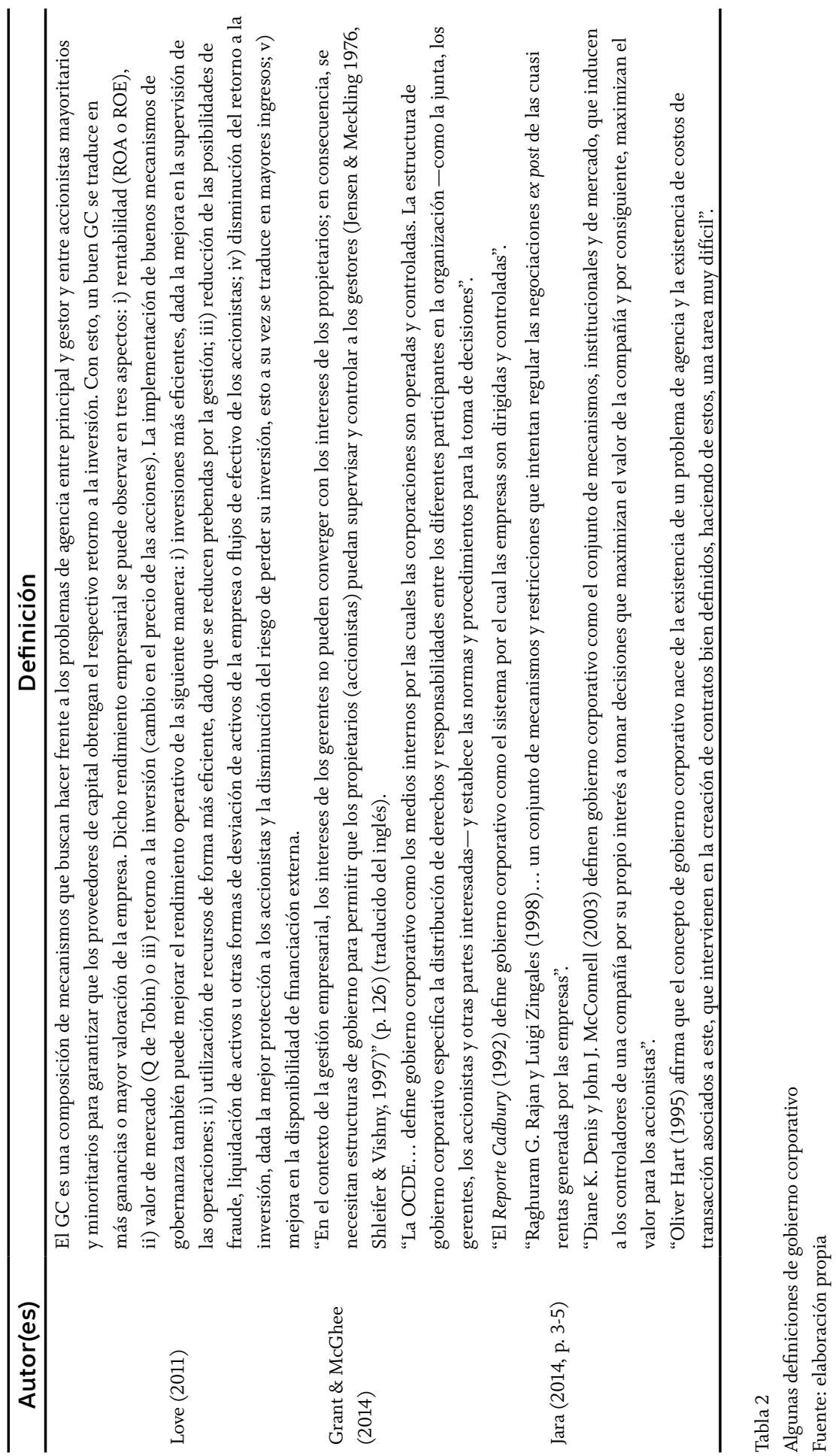


El esfuerzo de la Organización para la Cooperación y el Desarrollo Económicos (OCDE) ha sido fundamental para la difusión de los principios de GC, pues esta ha liderado diferentes grupos de trabajo que han producido lineamientos de GC de alta aceptación. Actualmente, en su $3^{\text {ra }}$ revisión (1999, 2004 y 2015), estos principios abarcan temas relacionados con 1) los derechos de los accionistas y su tratamiento equitativo, 2) el papel de los grupos de interés, 3) revelación de información y transparencia, y 4) las responsabilidades de la junta. Aunque la OCDE establece recomendaciones específicas para cada temática que buscan garantizar una toma adecuada de decisiones ajustada al marco legal específico de la empresa, la posición de esta organización se puede rastrear hasta el modelo anglosajón de gobierno corporativo, en el que prima la generación de valor para los accionistas en un marco regulado por la teoría de agencia, contrario al modelo de Europa Continental que privilegia la regulación interna de la firma como resultado de la influencia de las leyes que rigen la corporación y el ámbito laboral (Aglietta \& Rebérioux, 2005).

Para Michel Aglietta y Antoine Rebérioux (2005), la defensa a ultranza de los intereses de los accionistas (valor para el accionista) ha dejado a los administradores sin un control real de su gestión, lo que ha potenciado la inestabilidad de los mercados y los fraudes empresariales. A diferencia de los argumentos de Sanford J. Grossman y Oliver D. Hart (1986), que asignan los derechos de control a los accionistas como resultado de su desprotección, dada su naturaleza de reclamantes residuales de los flujos de caja, Aglietta y Rebérioux consi- deran que la posibilidad de diversificación y liquidez de los mercados son suficientes para reducir la prioridad de los accionistas e incorporarla en un objetivo consensuado. Este objetivo, producto de la negociación entre las partes y del reconocimiento de la naturaleza política de la firma (que va más allá de un nexo de contratos), debe incorporar necesariamente otros grupos de interés, en particular a los empleados (en concordancia con el sistema de codeterminación alemán). El impacto del cambio de objetivo se debe observar en la estructura de junta, con la presencia de directores asalariados, los cuales generan un debate (informado) ex ante sobre las acciones de la administración, y no un control ex post, característico del modelo de valor para el accionista con énfasis en la independencia de los directores (cuya debilidad es precisamente el desconocimiento de la firma). De esta forma, el objetivo a maximizar para los administradores sigue siendo debatido hasta la actualidad, con diferentes connotaciones, como la concentración de la propiedad, característica de la mayoría de los mercados, y la baja liquidez de las acciones que mina una de las protecciones esenciales de los accionistas asumida.

Ahora bien, independiente del debate sobre el objetivo de la firma, los códigos de GC realizan recomendaciones específicas sobre el accionar de las firmas que buscan reducir la asimetría de información frente a los mercados, como la divulgación de la estructura de propiedad, la revelación de información transparente y los estándares aceptados internacionalmente. Sobre la estructura y el tamaño de las juntas que garantice una operación eficiente e inde- 
pendencia de la misma: como un tamaño estándar entre 5 y 9 integrantes (Guest, 2009), un número suficiente de miembros independientes (en este caso, la evidencia es mixta: Sanjai Bhagat y Bernard S. Black (1999), y Benjamin E. Hermalin y Michael S. Weisbach (1991) no encuentran evidencia positiva de la presencia de directores independientes; mientras que Shams Pathan, Michael T. Skully y Jayasinghe Wickramanayake (2008) y Stuart Rosenstein y Jeffrey G. Wyatt (1990) reportan lo contrario). En la adopción de estas recomendaciones, los países han decidido imponer algunas vía legislación y otras vía autorregulación. En Colombia, la Ley 964 de 2005 y la adopción del código país son evidencia de esta estrategia. La Ley 964 de 2005 acogió las recomendaciones sobre independencia y tamaño de junta (entre otras), mientras el código país incorporó las relativas a transparencia y reglas de funcionamiento de los órganos de control.

El Código País de Colombia y su encuesta anexa, la cual aplica para empresas listadas en bolsa, fue desarrollado bajo el liderazgo de la Superintendencia Financiera. En su revisión de 2014, el código realiza recomendaciones sobre: 1) derechos de los accionistas, 2) asamblea, 3) junta directiva, 4) arquitectura de control, y 5) transparencia de información. Esta estructura se acerca a las recomendaciones de la OCDE. Para empresas cerradas y familiares, la Confederación Colombiana de Cámaras de Comercio lideró el desarrollo de la Guía colombiana de gobierno corporativo para sociedades cerradas y de familia (2009), enfocada en la creación de estructuras mínimas que garanticen una gestión adecuada en lo relativo al máximo órgano social (usualmente la Asamblea), el control de gestión y los administradores incluyendo a la junta directiva.

\subsection{Desempeño financiero y gobierno corporativo}

Los beneficios tangibles de altos niveles de gobierno corporativo tradicionalmente se asocian con un mejor desempeño financiero. Las razones son diversas. Desde el punto de vista de la teoría de agencia, al minimizarse los beneficios privados de los administradores y accionistas en control y tomar decisiones orientadas a la maximización del valor para toda la empresa, mejoran las perspectivas de crecimiento (mayor capacidad de reinversión) y se reduce la percepción de riesgo por parte de los interesados externos. En consecuencia, es posible que un buen nivel de GC reduzca el costo de capital de la empresa, lo que incrementa la propensión de acreedores y accionistas a proveer recursos. Al reducirse la percepción de riesgo por parte de tenedores de bonos y bancos, es esperable que las tasas a las que estos estén dispuestos a financiar la empresa se reduzcan. Igual argumento cabe para los accionistas. Adicionalmente, si las empresas están restringidas en su endeudamiento, por los mismos motivos, puede producirse un cambio en el apalancamiento (Benavides-Franco \& Mongrut-Montalván, 2010), o complementariamente, el nivel de endeudamiento óptimo podría incrementarse. Desde la óptica de la teoría de trade-off de la estructura de capital $^{14}$

14 La teoría del trade-off de la estructura de capital (Easterbrook, 1984; Fama \& French; 2002; Kraus \& Litzenberger, 1973) postula que el endeudamiento produce beneficios y costos. Los beneficios de la deuda son el escudo fiscal y la mayor exigencia sobre la administración para cumplir el 
los costos incrementales de mayores niveles de deuda se reducen, por lo que en forma óptima la empresa puede (debe) tomar un mayor nivel de deuda. Desde el punto de vista de la teoría del stewardship, sin conflictos de agencia o con estos al mínimo, y con una visión de largo plazo como objetivo de maximización, debería también presentarse una relación positiva entre niveles de gobierno y desempeño. En la visión de Michel Aglietta y Antoine Rebérioux (2005), los estándares de GC, respondiendo a un objetivo de optimización diferente, se asociarían con el desempeño. En este modelo de los retornos financieros positivos ${ }^{15}$, no necesariamente se asocian con mejor desempeño, pues estos autores abogan por un modelo de GC diferente, resultado de la visión de la empresa como un partnership y un objetivo de maximización resultado de la negociación entre los grupos de interés. Si este argumento se acogiera, un estudio sobre la asociación entre GC y el desempeño debiera incorporar proxies diferentes tanto para esta variable como para el GC.

Por otro lado, al incrementarse las expectativas de crecimiento, la relación entre valor de mercado y valor en libros crecerá, lo que induce una asociación positiva y causal con la $\mathrm{Q}$ de Tobin (La Porta, López de Silanes, Shleifer \& Vishny, 2002; Villalonga \& McGahan, 2005).

Tanto mejores reglas para toma de decisiones (en junta directiva y/o asamblea de ac-

servicio de la deuda, entre otros; mientras que los costos son fundamentalmente el riesgo de bancarrota. La estructura óptima está dada por un balance entre los costos y los beneficios.

15 Estos retornos financieros podrían asociarse a mayor apalancamiento e inestabilidad, fruto de la falta de supervisión de la gerencia. cionistas), como estructuras de propiedad que reduzcan los conflictos de interés pueden incrementar la eficiencia operativa de la empresa, al incrementar los rendimientos o reduciendo el exceso de activos por lo que la rentabilidad sobre los activos ROA, o la rentabilidad sobre el patrimonio ROE deberán subir (BenavidesFranco \& Mongrut-Montalván, 2010; Chen \& Nowland, 2010; Ramdani \& Witteloostuijn, 2010). Adicionalmente, un incremento en el apalancamiento se refleja en un mayor retorno sobre el patrimonio.

Otras características relativas al gobierno corporativo y su efecto en el desempeño también han sido estudiadas. La concentración y el tipo de propiedad están entre las más recurrentes. El efecto de la concentración de propiedad en el desempeño tiene beneficios y costos. Si se habla del porcentaje de propiedad en manos del administrador, se considera que un mayor porcentaje genera una mayor alineación con los objetivos de los otros propietarios por lo que el efecto en el desempeño debiera ser positivo. Sin embargo, niveles muy altos pueden generar un atrincheramiento de la gerencia, una indiferencia por el impacto en la empresa de las fuerzas disciplinarias del mercado, en términos de su valoración (y posibilidades de control) (Stulz, 1988). En términos de concentración de la propiedad por parte de bloques de accionistas, el efecto tiene varias aristas. Si el bloque de acciones no es controlante, se espera un impacto positivo en el desempeño, debido a que su presencia implica un efecto disciplinario sobre la administración en términos de monitoreo y control, pues los incentivos del bloque de acciones eliminan el problema del free-rider 
en términos de realizar un esfuerzo cuyos beneficios se diluyen entre todos los propietarios (Shleifer \& Vishny, 1997).

Cuando el bloque de acciones es controlante, el efecto de una mayor concentración está asociado con la diferencia entre los derechos de control y los derechos sobre los flujos de caja de la empresa. A mayor diferencia menor efecto positivo en el desempeño, pues el conflicto de interés entre accionistas controlantes y no controlantes se agudiza. Stijn Claessens, Simeon Djankov, Joseph P. Fan y Larry H. Lang (2002) encuentran un efecto positivo en el valor de la empresa ( $Q$ de Tobin) a mayor concentración de la propiedad, efecto que se reduce cuando hay diferencia entre los derechos de control y los de flujo de caja.

Belén Villalonga y Anita M. McGahan (2005) dividen los costos de agencia en dos tipos: los resultantes de las decisiones oportunistas del administrador en control contra el propietario (Tipo I) y los resultantes de las decisiones oportunistas de los accionistas en control contra los accionistas minoritarios (Tipo II). En su razonamiento, concluyen que cuando el accionista controlante es a su vez una empresa con propiedad dispersa, un banco o un fondo de inversión, con bajos incentivos de expropiación y/o de monitoreo, el costo Tipo I predomina; mientras que si el accionista controlante es una familia o un individuo, predomina el Tipo II. En términos de esta taxonomía, la diferencia entre derechos de caja y derechos de control es un costo Tipo II, los cuales serían los costos de agencia más comunes en América Latina y Colombia, dada la alta concentración de la propiedad accionaria y la presencia de familias en control y tendrían un impacto importante en el desempeño. Estos autores encuentran un efecto positivo en la Q de Tobin de la presencia de control familiar, y un impacto negativo de las estrategias para mantener el control y de las limitaciones de los derechos de los accionistas.

\section{Revisión de documentos}

En esta sección se elabora el análisis de los estudios empíricos en países desarrollados y en desarrollo, con énfasis en Latinoamérica y Colombia. Estos documentos hacen parte de la corriente principal de estudios de GC y son impulsados por el eje teórico del problema de agencia.

\subsection{Estudios empíricos en países desarrollados}

Algunos autores han dedicado sus análisis a determinar los beneficios empresariales que conllevan tener un adecuado GC. Entre los estudios más relevantes se encuentra el de Rafael la Porta, Florencio López de Silanes, Andrei Shleifer y Robert W. Vishny (2002). En este artículo se explora el origen de las normas legales de protección a los accionistas y acreedores de 49 países en 1993; estas diferencias se marcan a partir del origen legal del país (derecho común o derecho civil). Este estudio muestra notables diferencias en las leyes en todo el mundo: el punto en común es la limitada protección a los inversionistas. Estos autores indican que los países con legislaciones provenientes de common law tienden a proteger más a los proveedores de capital, aplican las leyes con más fuerza y argumentan que tienen mejores normas contables 
en comparación con los países de derecho civil $^{16}$. Además, la concentración de capital que se origina mayoritariamente en países con legislación proveniente del derecho civil y que en general son más desiguales, está relacionada de manera negativa con la protección a los inversionistas.

No obstante, Holger Spamann (2008, 2010) indica que el origen de la legislación de los países no necesariamente tiene la importancia que le atribuyen Rafael la Porta, Florencio López de Silanes, Andrei Shleifer y Robert W. Vishny (1998), sino que esta protección legal debe ser medida a partir de otro tipo de metodologías sin generalizar a partir del origen legal ${ }^{17}$.

Por otro lado, un estudio relacionado con la estructura de propiedad de las corporaciones es el de Rafael La Porta, Florencio López de Silanes y Andrei Shleifer (1999) que explica las diferencias entre los países en sus formas de propiedad y control, partiendo de aquellas que utilizan la forma de control del tipo Adolf A. Berle y Gardiner C. Means ${ }^{18}$. Estos autores estudiaron 691 empresas ubicadas en las 27 economías más ricas del mundo durante el período 1995-1997. En este estudio se encuentra que la mayoría de los países en los que es común encontrar corporaciones del tipo Berle y Means hay una mejora

16 Colombia figura entre estos últimos.

17 Implícitamente reconociendo la debilidad del índice inicial, Simeon Djankov, Rafael La Porta, Florencio Lópezde-Silanes y Andrei Shleifer (2008) producen el nuevo índice "anti-self-dealing" que, de acuerdo a los autores, produce mejores resultados que el calculado en su documento inicial.

18 "Una gran cantidad de accionistas pequeños, propietarios de acciones comunes, que no tengan otro rol en la empresa y que deleguen su autoridad en un directorio y un grupo de ejecutivos" (Lefort, 2003). en los precios de las acciones, el mercado de capitales es más valioso y los países son más ricos. Adicionalmente, concluyen que en la mayoría de los países las empresas con estructura piramidal son controladas por familias. Esto lleva a que los accionistas controladores tengan control por encima de sus derechos de flujo de efectivo, dado que por sus estructuras piramidales son al tiempo accionistas y gestores.

El estudio de Abe de Jong, Douglas V. DeJong, Gerard Mertens y Charles E. Wasley (2005) centra su análisis en la autorregulación. Este tiene como objetivo analizar las características del GC, a partir de los lineamientos de la iniciativa de The Peters Committee (1997, 2003) basados en la autorregulación de empresas holandesas del sector privado. Entre sus conclusiones principales están que para que la autorregulación tenga éxito los accionistas deben tener derecho a voto, debe haber una fuerte vigilancia de las empresas; además, el mercado proporciona una gestión con incentivos e imposición de penas para que las empresas mejoren su gobernanza.

Entre los estudios en los que se abordan la construcción de índices de GC se encuentra el de Lawrence C. Brown y Marcus L. Caylor (2004a). Este estudio tiene como propósito elaborar un índice de GC y observar la relación con algunas variables de desempeño financiero clasificadas en tres categorías: i) desempeño operativo (rentabilidad sobre recursos propios, margen de beneficio y crecimiento de las ventas), ii) pago a los accionistas (rentabilidad por dividendo y recompra de acciones), y iii) valoración de la firma ( $Q$ de Tobin). Algunos de los resultados más relevantes de este estudio 
son que las empresas con tamaño de junta entre seis (6) y quince (15) personas tienen una mayor rentabilidad sobre el capital y los márgenes de beneficios netos más altos que las empresas que tienen otros tamaños de junta. Por otro lado, las empresas con GC relativamente pobre son relativamente menos rentables (menor rentabilidad sobre recursos propios y margen de beneficio), presentan menor valoración ( $\mathrm{Q}$ de Tobin más pequeña) y pagan menos dinero en efectivo a sus accionistas (menor rentabilidad por dividendo y baja recompra de acciones). Para tal fin se analizan las empresas que para 2002 hacían parte de la medición del Institutional Shareholder Services (ISS) con un total de 2.327 empresas y se extrae la información para el 1 de febrero de 2007. Su método de estimación consiste en correlaciones de Pearson y Spearman de un índice de GC, elaborado por los autores y las variables financieras elegidas.

Adicionalmente, estos autores elaboran una revisión de elementos de GC relacionados con el desempeño de las organizaciones y encontraron relaciones positivas entre el GC y los indicadores de rendimiento como valoración del mercado, costo de deuda o valor de las acciones (Baysinger \& Butler, 1985; Brickley, Coles \& Terry, 1994; Rosenstein \& Wyatt, 1990; Yermack, 1996, citados por Brown \& Caylor, 2004a). Además encuentran relaciones negativas entre prácticas de GC elementos como el costo de deuda, indicadores de rentabilidad y retribución al gestor (Anderson, Mansi \& Reeb, 2004; Core, Holthausen \& Larcker, 1999; Frankel, Johnson \& Nelson, 2002; Jensen, 1993; Klein,
2002; Lipton \& Lorsch, 1992; Yermack, 1996, citados por Brown \& Caylor, 2004a).

En otro estudio, Lawrence C. Brown y Marcus L. Caylor (2004b) buscan examinar si la fortaleza del GC impacta en el rendimiento de la empresa. Para tal fin se exploran 5.460 empresas para 2003. En este estudio se encuentra que las empresas con GC débil son menos rentables, específicamente tienen menor rendimiento de los activos, además son más riesgosas, tienen precios de las acciones más volátiles y retribuyen con dividendos más bajos que las empresas con un fuerte GC.

Paul A. Gompers, Joy L. Ishii y Andrew Metrick (2003) construyen un índice de gobierno como indicador del nivel de derechos de los accionistas en 1.500 empresas grandes durante los años 90 en Estados Unidos y encontraron que las empresas con altos niveles de derechos a los accionistas tenían un mayor valor, unas ganancias más altas, un alto crecimiento en las ventas, relativamente bajas inversiones de capital y realizaban pocas adquisiciones. También hallaron evidencia de que las empresas con débiles derechos para los accionistas eran menos rentables y tenían un menor crecimiento en sus ventas en comparación con otras empresas de la industria.

Por otro lado, el estudio de Inessa Love (2011) hace una conceptualización de GC a partir de la revisión de la literatura y elabora un recorrido por el tratamiento de datos en las investigaciones de $\mathrm{GC}$ y las posibilidades de corrección de problemas metodológicos. Este documento tendrá un mayor abordaje en la sección de tratamiento de la endogeneidad. 
Al confirmar la asociación entre altos niveles de GC y desempeño financiero, Jackie Krafft, Yiping Qu, Francesco Quatraro y Jacques-Laurent Ravix (2014) hallaron que los retornos accionarios, el rendimiento de los dividendos, el ROA y el margen de utilidad neta responden positivamente a mejoras en los índices de gobierno, lo mismo que la $\mathrm{Q}$ de Tobin para un panel de firmas en 24 países y sectores industriales entre 2003 y 2008. Estas muestras corresponden a países desarrollados de Europa además de Hong Kong, Japón, Australia y Nueva Zelanda. El índice de GC utilizado es calculado por RiskMetrics sin intervención de las empresas y pondera más de 50 características de GC. Los resultados son robustos a diferentes tratamientos y pruebas de endogeneidad.

En conjunto, los artículos incluidos en este acápite respaldan la tesis de un mejor desempeño asociado con niveles más altos de GC, en estudios que cubren análisis el nivel de país y el nivel de firma.

\subsection{Algunos estudios empíricos en países emergentes}

Stijn Claessens, Simeon Djankov, Joseph P. Fan y Larry H. Lang (2002) estudian la relación entre los derechos de flujos de caja, los derechos de control y el valor de la firma para $1.301 \mathrm{em}$ presas listadas en bolsa pertenecientes a ocho economías de Asia Oriental. Sus resultados apuntan a un mayor valor de la empresa asociado con la propiedad de los derechos de flujo de caja del mayor accionista y un efecto negativo cuando sus derechos de control exceden los de flujos de caja.
Por su parte, Karl V. Lins (2003) estudió 1.433 firmas de 18 países emergentes entre 1995 y 1997 y encontró que desviaciones de los derechos de flujos de caja frente a los derechos de voto de la administración reducen el valor de la firma, mientras que bloques de acciones y derechos de control no asociados con la administración lo incrementan. Estos efectos son más pronunciados en países con bajo nivel de protección al inversionista.

Por otro lado, Leora F. Klapper e Inessa Love (2004) estudiaron los determinantes y las diferencias entre 374 empresas de países emergentes para 1999 en el nivel de gobernanza de las empresas y el rendimiento operativo y valoración de mercado a partir de las prácticas de GC. Ellas encontraron que hay mayor variación en el nivel de gobernanza de las firmas en los países con sistemas legales débiles; las firmas ubicadas en países con un sistema legal débil podrían no tener mucha flexibilidad para mejorar su protección a los accionistas y además podrían tener unos bajos índices de GC; hay un aumento en el índice de gobernanza cuando las empresas ubicadas en países con un sistema jurídico débil emiten ADR (American Depositary Receipt); el grado de variación de gobernanza dentro de los países no está sistemáticamente relacionado con la medida de la efectividad legal del país; además, las empresas por sí mismas no son capaces de producir por completo un buen ambiente legal por su cuenta vía autorregulación, sino que dependen de un sistema judicial eficiente de apoyo; finalmente, las empresas que negocian acciones en Estados Unidos tienen un mejor índice de GC, sobre todo en los países con sistemas legales débiles. 
Luego, Leora F. Klapper, Luc Laeven e Inessa Love (2005) investigaron los determinantes de las diferencias en los mecanismos de GC de las empresas orientados a la protección de los accionistas minoritarios en 224 empresas de cuatro países de Europa del Este en el período de 1989 a 1995. Entre sus resultados más relevantes está que las empresas de propiedad extranjera regularmente están obligadas a cumplir altos estándares de GC y, por tanto, tienen más probabilidades de adoptar disposiciones más estrictas de gobernanza; encontraron también que los efectos reputacionales de las empresas extranjeras son mayores si proceden de países donde la ley prescribe un mayor conjunto de disposiciones de GC que el país de acogida.

Roszaini Haniffa y Mohammad Hudaib (2006) se enfocaron en encontrar la relación entre la estructura de GC y el desempeño de 347 empresas de Malasia entre 1996 y 2000. Sus resultados sugieren que el mercado percibe las juntas directivas grandes como ineficaces y que tienden a ser simbólicas en lugar de ser parte de un proceso real de gestión; hay mejores rendimientos en el mercado cuando la mayor parte de los directores de la junta directiva no hacen parte de la administración; el desempeño es mejor cuando la propiedad está dispersa, dado que las participaciones de capital concentradas en pocos accionistas llevan a una vigilancia ineficaz debido a los conflictos de intereses; el mercado percibe el apalancamiento financiero como una forma eficaz para controlar la gestión y mejorar el rendimiento; otros resultados apuntan a la ineficiencia de las juntas directivas grandes, no obstante su valor como proveedores de recursos y conocimiento. Encontraron además que la ma- yoría de los administradores independientes no son seleccionados por su experiencia, sino por razones políticas como legitimar las actividades empresariales o mejorar contactos y contratos. Por tanto, estos directores no son capaces de contribuir al monitoreo independiente y reducir los conflictos de agencia asociados a una mala asignación de recursos. Finalmente, en este mercado, la propiedad concentrada presenta mayores rendimientos que la dispersa; no obstante, el mercado percibe lo contrario; esta situación no es la ideal para un mercado emergente que trata de atraer inversionistas y fomentar la dispersión accionarial.

Otro estudio realizado en Europa del Este es el de Marek Gruszczynski (2006). Esta investigación tiene como objetivo examinar la relación entre el nivel de GC y el desempeño financiero de 37 sociedades de la Bolsa de Valores de Varsovia en 2003. Este estudio confirma que el grado de GC está correlacionado con su desempeño financiero. Además, hay una asociación significativa entre la calificación del GC con el margen de utilidad de operación y el índice de apalancamiento.

Stijn Claessens y Burcin Yurtoglu (2013) revisaron extensamente la literatura sobre GC en países emergentes. Concluyeron que las firmas con mejores niveles de GC tienen mayor acceso al financiamiento, un menor costo de capital, mejor desempeño y tienden a tener mejores relaciones con otros grupos de interés (como los empleados). Empresas con mejores prácticas de GC reportan menores retornos negativos en tiempos de crisis. Así mismo, encontraron que la efectividad de la autorregulación es menor si el sistema de gobernanza del país es débil. Stijn Claessens y 
Burcin Yurtoglu (2013) reportaron diferencias entre indicadores de gobierno entre países desarrollados y emergentes, que cubren los derechos legales de los inversionistas y la opacidad de las prácticas y la información financiera. En la tabla 3 se comparan los valores promedio de países emergentes frente a los desarrollados. Los países emergentes igualan a los desarrollados en los indicadores de derechos de los acreedores, protección de los accionistas minoritarios y apertura de información, pero son superados, de manera crucial, en la fortaleza de los derechos legales, efectividad del cumplimiento con los acreedores, la prevalencia de la corrupción y la opacidad de las prácticas de gobierno. Con la salvedad de grandes diferencias entre los puntajes de los países emergentes y los bajos puntajes de Colombia (excepto en el trato hacia los acreedores), el desafío estriba en la efectividad de las reformas para promover un ambiente de confianza que promueva la inversión y la liquidez de los mercados accionarios. Los estudios revisados por Stijn Claessens y Burcin Yurtoglu (2013) también sugirieron la prevalencia de las estructuras de propiedad concentradas y la afiliación a grupos de negocios en los países emergentes. En cuanto al punto de convergencia de las prácticas de GC, los estudios sugieren que la emisión de guías de gobierno tiende a darse en países con mayor grado de liberalización, pero que esta convergencia es más de forma que efectiva.

\subsection{Estudios en América Latina}

En América Latina, al igual que el resto de los países en desarrollo, el GC ha tenido matices particulares, principalmente por las dificultades que sobrevienen con el contexto y la cultura. En los documentos a continuación se observa el tipo de organización dominante en la región, sus formas de gestión y el impacto en el desarrollo del GC.

Fernando Lefort (2003) desarrolló un marco conceptual en el que discute los sistemas legales que están detrás de las estructuras de GC se enfocan en la composición de este en las economías latinoamericanas. Puntualiza la importancia del grado de protección a los inversionistas y el desarrollo del mercado de capitales en la conformación de las empresas cuya propiedad está separada del control. Lefort argumenta que este tipo de corporaciones permite eliminar el problema de freerider, además de disminuir los costos de un mal sistema de incentivos o mala asignación de capital frente a los conglomerados ${ }^{19}$ que son comunes en países en desarrollo. No obstante, el autor señala que este tipo de organización (conglomerado) y su continuidad en el tiempo en economías emergentes presentan algunos beneficios comparados con otro tipo de estructuras, como poder político que permite soslayar la corrupción y la burocracia, además de combatir los problemas de mercado dada la asimetría de información, faltas en la regulación y vigilancia y el bajo desarrollo de los mercados de capitales. Por otro lado, el autor hace una crítica acerca de las recomendaciones de la OCDE para el buen GC entre las que menciona una estructura demasiado rígida de GC y la desmedida importancia de los accionistas por encima de los demás stakeholders.

19 "Grupo de empresas dedicadas a negocios no necesariamente relacionados, pero que tienen un controlador o accionista mayoritario común o que se encuentra relacionado mediante pactos o sociedades. Estos conglomerados ejercen control sobre las empresas afiliadas mediante estructuras piramidales, series accionarias preferentes y tenencias cruzadas de acciones" (Lefort, 2003, p. 216). 
GOBIERNO CORPORATIVO Y DESEMPEÑO FINANCIERO / N. ESCOBAR, J. BENAVIDES, H. PERAFÁN / 229

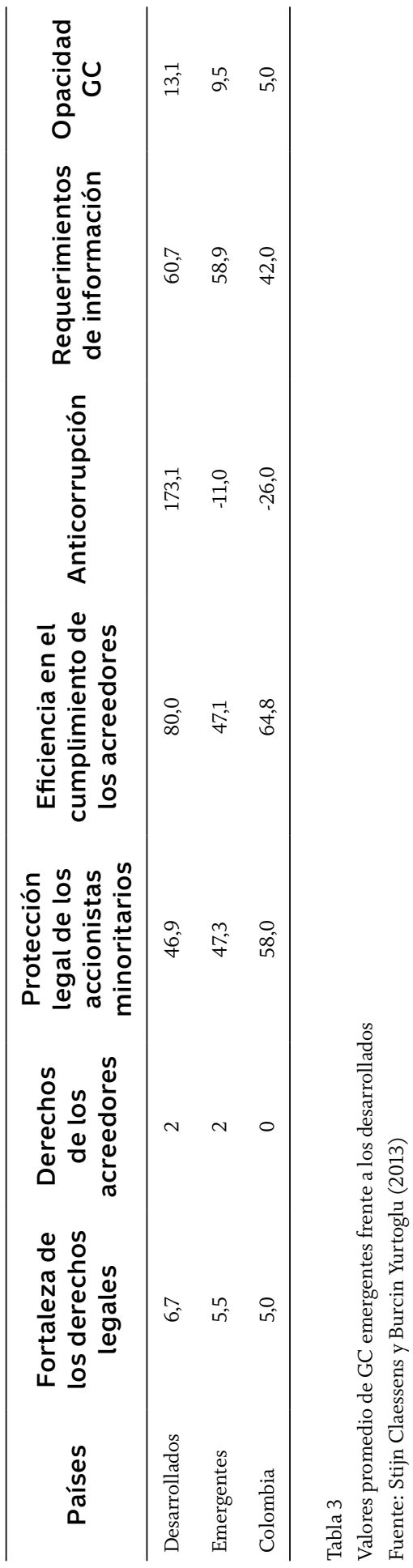


Ricardo P. C. Leal y André L. Carvalhal da Silva (2004) construyeron un índice de GC basado en información pública de las empresas que cotizan en la Bolsa de São Paulo, en el período 1998-2002, y encontraron que las empresas brasileñas tienen un mejor desempeño en lo que respecta a la revelación de información que en otros aspectos del GC. Adicionalmente, presentan una alta concentración de la propiedad. Por último, concluyen que un buen GC está positivamente correlacionado con un mayor valor de las corporaciones en Brasil.

Urbi Garay, Germán González, Maximiliano González y Yelhis Hernández (2006) estudiaron la relación entre GC y desempeño para 46 empresas venezolanas en 2004. Encontraron que aquellas con mayores índices de GC presentaban mejores resultados financieros medidos por la razón de pago de dividendos, precio de mercado de las acciones a valor en libros y Q de Tobin.

Por otra parte, Richard A. Price, Francisco J. Román y Brian R. Rountree (2006) elaboraron una investigación sobre la relación entre transparencia, calidad de la información e información financiera de acuerdo a su nivel de GC. Las estimaciones se hacen por medio de un análisis multivariado en el que se utiliza una muestra de 107 empresas no financieras que cotizan en la Bolsa de Valores Mexicana durante el período de 2000 a 2004. Los resultados no muestran una relación significativa entre las variables estudiadas; no obstante, a partir de sus hallazgos, los autores concluyeron que México debe complementar sus políticas con mecanismos alternativos que permitan mejorar la transparencia informativa, dado que las políticas actuales no son fuertes y a pesar de la mejora durante los años de estudio en el índice de GC elaborado por estos investigadores, no hay una notable mejora en la transparencia y calidad de la información financiera revelada.

Otro estudio en el que se hace una profunda revisión de la literatura de esta temática en América Latina es el de Luis Hernando Gutiérrez, Carlos Pombo y Rodrigo Taborda (2008). Estos autores encontraron que en Chile hay un alto grado de concentración corporativa y una baja relación deuda/capital, además describen la importancia de la Ley 19705 de 2000 en la evolución de prácticas de GC en contraste con el marco jurídico planteado en los años 90 (Agosin \& Pastén, 2003; Apreda, 2000, citados por Gutiérrez, Pombo \& Taborda, 2008). Por otro lado, en Brasil describen que a pesar de la adopción de buenas prácticas emitidas por el Instituto Brasileño de GC hay una mala gobernanza en este país, además explican que en dicho país la legislación de GC está centrada en determinantes legales de composición accionaria con las votaciones y poderes sin derecho a voto, además de en el grado de protección de los accionistas (Claessens, Klingebiel \& Lubrano, 2000; Pinheiro Neto Advogados, 2000; Saito, 2000; citados por Gutiérrez, Pombo \& Taborda, 2008).

Julián Benavides-Franco (2005) estudió la concentración de la propiedad y el desempeño contable en un panel de datos de 532 empresas entre 1999 y 2003 de cinco países latinoamericanos: Colombia, Brasil, Chile, Perú y Venezuela. Los resultados, en una aproximación que asume independencia entre las variables de interés, sugieren un efecto positivo de 
la concentración de la propiedad sobre el desempeño y un efecto, más débil, también positivo, del desempeño sobre la concentración de la propiedad. En un contexto de ecuaciones simultáneas, el efecto de la concentración de la propiedad en el desempeño se torna negativo, mientras que el efecto positivo del desempeño sobre la concentración de la propiedad se desvanece. La relación de la concentración de la propiedad con el desempeño sugiere un atrincheramiento de los accionistas controlantes que vulnera la competitividad de las empresas de los países de la muestra.

Para un panel de firmas peruanas, Julián Benavides-Franco, Samuel Mongrut-Montalván y Mónica González-Velasco (2012) estudiaron la relación entre la concentración de la propiedad, la propiedad familiar, la administración y el desempeño contable y bursátil de 59 empresas industriales listadas en la Bolsa de Valores de Lima. Los datos van de 1999 a 2005. Estos investigadores encontraron una relación en forma de U inversa entre la concentración de la propiedad y el funcionamiento del mercado, presente en empresas familiares y no familiares, lo que señala un efecto atrincheramiento o excesiva aversión al riesgo del grupo de control. El efecto se agrava para las empresas familiares. La presencia de CEO, presidente de la junta e integrantes de la junta familiares también es negativa para el rendimiento. La propiedad familiar aumenta el apalancamiento.

\subsection{Estudios empíricos en Colombia}

El estado del GC en Colombia pasa por los esfuerzos de los reguladores y de los entes de control. La Confederación de Cámaras de Co- mercio lideró hacia principios del milenio el desarrollo de las primeras recomendaciones de GC. La Ley 964 de 2005 definió unos requisitos mínimos de ley para las empresas listadas, que se unió al requerimiento del ya comentado Código País, por parte de la Superintendencia Financiera. El ente de control que supervisa las sociedades anónimas no listadas, la Superintendencia de Sociedades, requiere anualmente el diligenciamiento de una encuesta que también cubre estos temas. Hoy existen diferentes guías de gobierno que fueron desarrolladas por estos entes, con el propósito de apoyar empresas cerradas y familiares. La baja presencia de empresas en la bolsa de valores y los bajos niveles de endeudamiento son característicos de economías con bajo desarrollo de su sistema financiero, lo que limita el impacto de mayores exigencias de GC. El puñado de empresas activas en este sentido se limita a aquellas que generan la liquidez del mercado de acciones.

Uno de los primeros estudios en analizar si mejores prácticas de gobierno conducen a un mejor rendimiento es el de Luis Hernando Gutiérrez y Carlos Pombo (2007), la muestra corresponde a 431 empresas cerradas entre 1996 y 2002. El estudio adicionalmente indaga sobre la relación entre la estructura de propiedad de las empresas y su valor, en este caso para una muestra de 108 empresas no financieras entre 1998 y 2002. Estos autores construyen un índice de GC, a partir de un cuestionario de 67 preguntas que se organizaron en cuatro criterios: principios generales, alta gerencia y junta directiva, accionista y divulgación.

Entre sus principales conclusiones, los autores destacan que en Colombia la concentración 
de capital es alta y aumentó durante los años de estudio, principalmente entre los cuatro accionistas más grandes. Así mismo, encontraron que la relación entre los derechos de flujo de efectivo y los derechos de voto es baja. Esto demuestra que el control corporativo es sesgado hacia los accionistas que tienen grandes bloques de acciones que finalmente son los que establecen las políticas de gestión en las empresas. Por otro lado, hay un notable papel de las empresas de inversión como accionistas mayoritarios; sin embargo, las grandes familias son las que están detrás de estas empresas, por lo que estas son las que finalmente se constituyen como propietarios finales de las grandes empresas. Por último, en este estudio no hay evidencia de que mejores prácticas de GC se traduzcan en mejores resultados financieros; no obstante, los investigadores mencionan que las empresas de este estudio se muestran renuentes a poner en práctica las recomendaciones del gobierno y las cámaras de comercio respecto al GC.

Andrés Langebaek y Jaime Eduardo Ortiz (2007) estudiaron el estado de las prácticas de GC en las empresas que negocian acciones ordinarias en la Bolsa de Colombia, para lo cual construyeron su propio índice: el Índice de Gobierno Corporativo, IGC. Adicionalmente, midieron el impacto que las buenas prácticas de GC tienen sobre los costos de financiación del capital de las empresas. La muestra utilizada es de 57 empresas que negociaban acciones ordinarias en la Bolsa de Colombia en 2005.

A grandes rasgos, las conclusiones de esta investigación son: i) el nivel promedio del índice no es alto, lo que sugiere que en promedio las empresas tienen un gran camino por recorrer para mejorar su GC, y ii) una importante dispersión del IGC revela una considerable heterogeneidad en las prácticas de gobierno de las firmas que cotizan en bolsa. iii) Empresas con mayor apalancamiento parecen no generar elevados niveles de estrés financiero ${ }^{20}$. Por el contrario, parece corroborarse la hipótesis de que mantener ciertos niveles de deuda presiona una buena gestión por parte de los administradores. iv) La inversión en publicidad de una empresa genera una mejor valoración por parte de los inversionistas. Esta circunstancia puede deberse a la contribución de estos gastos a las ventas y a las utilidades futuras o a la mayor reputación que adquiere la empresa. v) Los inversionistas valoran más aquellas empresas que han tenido buenos resultados económicos recientemente (específicamente en el ROA).

En otro sentido, el artículo elaborado por Luis Hernando Gutiérrez, Carlos Pombo y Rodrigo Taborda (2008) se centró en la propiedad empresarial en Colombia durante la última década del siglo XX. En este estudio, expusieron los principales grupos empresariales del sector real de Colombia como el Sindicato Antioqueño, el grupo Santo Domingo y el grupo Ardila Lülle. La muestra fue de 140 empresas no financieras y el período estudiado es de 1996 a 2002. Los autores observaron que la concentración de la propiedad ha aumentado considerablemente en el último período de estudio y que alrededor del $40 \%$ de las empresas son

20 Estos autores definen el estrés financiero como dificultades que enfrentan las firmas en una guerra de precios con sus competidores o la exposición de pérdidas en coyunturas de altas tasas de interés (Opler \& Titman, 1994, citados por Langebaek \& Ortiz, 2007). 
familiares, además que en Colombia las empresas de inversión y los fondos fiduciarios juegan un papel fundamental dentro de la composición de la propiedad; concluyeron que en las instituciones financieras los accionistas tienen un papel limitado sobre el control en contraste con el verdadero poder del patrimonio de las familias. Adicionalmente, hallaron que en algunas empresas los accionistas mayoritarios no tienen los mayores derechos a voto, dado que los accionistas minoritarios arman bloques y se unen para formar la mayor propiedad accionaria. Finalmente, Luis Hernando Gutiérrez, Carlos Pombo y Rodrigo Taborda (2008) afirman que para Colombia no hay artículos para ese momento que analicen este tema; sin embargo, señalan la descripción que se hace de las empresas en el Informe Cadbury que menciona la falta de liquidez, la alta concentración de capital, la insuficiente información y la falta de transparencia en el mercado de capitales. Así mismo, evalúan el libro de María Angélica Arbeláez, Sandra Zuluaga y María Lucía Guerra (2002) que indica la importancia del CG, aunque de manera muy superficial. Adicionalmente, destacan el estudio descriptivo sobre grupos empresariales que se aproximan a la estructura corporativa, de Andrés Franco y Philippe André Achiel de Lombaerde (2000). Por último, se refieren al libro de Julio Silva-Colmenares (2004), que narra la historia de los grupos empresariales en Colombia.

Por último, el artículo de Julián BenavidesFranco y Samuel Mongrut-Montalván (2010) tiene como objetivo observar los efectos sobre el desempeño contable y las decisiones financieras en empresas colombianas después de implementar su código de gobierno, exigencia legal resultante de un cambio regulatorio e incorporada en el análisis como un factor exógeno, que permite incorporar inequívocamente la relación causal en GC y desempeño (o apalancamiento). La muestra de este estudio es de 43 empresas entre 1997 y 2006. Entre los resultados más importantes de este estudio están el aumento significativo del ROA después de implementar el código de GC: su efecto fue mayor entre mejor fuera la calidad del código. Así mismo, el endeudamiento de las empresas sube después de emitir el código y cuanto mejor sea su calidad. La conclusión general es que la autorregulación es eficaz como medio para inducir un compromiso de los accionistas controlantes para reducir sus rentas. En conclusión, los esfuerzos para mejorar las prácticas de GC se traducen en finanzas sólidas.

Maximiliano González, Alexander Guzmán, Carlos Pombo y María Andrea Trujillo (2015) estudian el efecto de la presencia de control familiar en el cambio del gerente para 596 empresas cerradas colombianas, entre 1996 y 2006. Encontraron que cuando las familias limitan su participación en la administración a su rol de propietarios, aumenta la rotación de los gerentes. Cuando participan en la gestión y/o en la junta, este efecto se reduce, lo que podría considerarse una falla de monitoreo, para la cual deberían buscarse soluciones. Además, utilizando una muestra de empresas similares, reportan un mejor desempeño de las empresas familiares sobre las no familiares cuando el fundador está aún involucrado en las operaciones.

Artículos en proceso de preparación sobre los efectos del GC en Colombia estudian 
el impacto del Código País para empresas listadas, lo mismo que el efecto de los niveles de GC en las empresas que reportan a la Superintendencia de Sociedades.

\subsection{Leyes relacionadas con el gobierno corporativo en Colombia}

Este apéndice hace una revisión histórica de la normatividad en materia de GC en Colombia.

Estas normas han evolucionado en coincidencia con la apertura económica que se implementó a partir de los años 90, lo que instó a desarrollar el mercado financiero, y a consolidar los inversionistas institucionales, cuyos activos representaban el 34,6\% del PIB para el año 2006, según el Banco Interamericano de Desarrollo, BID. Esto obligó a plantear requerimientos mínimos en materia de GC para realizar actividades de inversión en firmas nacionales. Los desarrollos más recientes — como el Código País de 2014-buscan elevar las exigencias y acercarse a las recomendaciones de la OCDE.

\begin{tabular}{|c|c|}
\hline Año & Descripción \\
\hline 1971 & $\begin{array}{l}\text { Código de Comercio: Busca regular la actividad comercial para todas las empresas en el país. Dentro del Código } \\
\text { de Comercio se pueden apreciar algunas aproximaciones que hacen referencia a los principios de GC; sin } \\
\text { embargo, no se hizo con la intención de mejorar la gobernabilidad de las empresas colombianas, sino de } \\
\text { organizar la actividad comercial. Los vacíos señalados en el Código de Comercio se relacionan principalmente } \\
\text { con los accionistas minoritarios y los stakeholders distintos a los accionistas. }\end{array}$ \\
\hline 1995 & $\begin{array}{l}\text { Ley 222: Tiene como objetivo renovar y mejorar las normas en temas de derechos de accionistas; revelación de } \\
\text { información, principalmente financiera; inclusión de los grupos interesados externos; y responsabilidades de } \\
\text { gestión relacionadas con los administradores y la junta directiva. }\end{array}$ \\
\hline 1998 & $\begin{array}{l}\text { Ley 446: En esta ley se incorporan normas que fortalecen la protección a los accionistas minoritarios. Entre } \\
\text { sus disposiciones más importantes está que un accionista minoritario puede solicitar intervención de la } \\
\text { Superintendencia de Valores, hoy Superintendencia Financiera, cuando sienta vulnerados sus derechos. }\end{array}$ \\
\hline 2001 & $\begin{array}{l}\text { Resolución } 275 \text { de Superintendencia de Valores, hoy Superintendencia Financiera: Esta norma va dirigida hacia } \\
\text { personas jurídicas que buscan que los fondos de pensiones adquieran sus valores. Busca prevenir, manejar y } \\
\text { divulgar los conflictos de interés a los que se enfrentan dichas organizaciones. }\end{array}$ \\
\hline 2003 & $\begin{array}{l}\text { Ley 795: Con esta ley se busca implementar algunos elementos de GC como información hacia los clientes, } \\
\text { revelación y transparencia de la junta directiva, y guías de manejo y prevención de conflictos de interés. }\end{array}$ \\
\hline 2005 & $\begin{array}{l}\text { Ley 964: Denominada Ley del Mercado de Valores, tiene normas orientadas principalmente a temas de GC. } \\
\text { Entre las más importantes se encuentra que el Gobierno Nacional podrá dictar normas relacionadas con el } \\
\text { GC, independencia y cantidad de miembros de la junta directiva, comité de auditoría obligatorio, sistemas } \\
\text { de votación distintos al cociente electoral, responsabilidades del representante legal y autorregulación para } \\
\text { organizaciones que realicen actividades de intermediación. }\end{array}$ \\
\hline 2007 & $\begin{array}{l}\text { Circulares Externas Superintendencia Financiera } 028 \text { y 056: Emisión de Código país que contiene una serie de } \\
\text { recomendaciones que se proponen por medio de su implementación mejorar las prácticas de GC para emisores } \\
\text { de valores. }\end{array}$ \\
\hline 2014 & $\begin{array}{l}\text { Código País y Adopción del Reporte de Implementación de Mejores Prácticas Corporativas. Este código busca } \\
\text { corregir y aclarar prácticas y preguntas en el Código de GC de } 2007 \text { y en su encuesta y alinear el GC colombiano } \\
\text { a requerimientos internacionales. }\end{array}$ \\
\hline
\end{tabular}

Tabla 4

Leyes empresariales en Colombia relacionadas con GC

Fuente: elaboración propia con base en Clemente del Valle y Mauricio Carvajal (2005) 
En estas normas se observa que hay una evolución de la normatividad, que converge hacia los estándares fijados por la OCDE, en términos del GC; sin embargo, hay un camino por recorrer para alcanzar estándares internacionales de países desarrollados y se debe tener en cuenta la posibilidad de implementar otro tipo de estándares procedentes de otros modelos como el continental-europeo o el nipón que no necesariamente comparten los estándares del modelo anglosajón con el que se formulan los estándares de la OCDE. La actualización del Código País en 2014 se realizó con el objetivo específico de adecuarse a estos estándares (Colombia, Superintendencia Financiera, 2014). La investigación sobre el efecto de estas leyes y de las prácticas de GC en las empresas colombianas se convierte en un elemento fundamental para el avance del GC en Colombia.

\section{Tratamiento de la endogeneidad desde la relación GC y desempeño financiero}

En el tratamiento de la información de GC suelen presentarse problemas de endogeneidad. La endogeneidad surge cuando las variables explicativas pueden a su vez haber sido determinadas por la variable dependiente. En el caso del GC, pudiera decirse que la variable utilizada como proxy de la estructura o nivel del GC (i.e., la variable específica que se asocia con él) en el desempeño financiero o en la toma de ciertas decisiones es, a su vez, afectada por las decisiones mismas. Esencialmente, se tiene un sistema de ecuaciones simultáneas, en el cual la dificultad radica en seleccionar de manera adecuada las variables exógenas cuyos errores sean ortogonales.

Esto supone un gran problema para los estudios empíricos que analizan la relación entre el GC y el desempeño financiero o la toma de decisiones financieras (en adelante, DF) de las compañías. Formalmente, en la medida en que los estimadores de mínimos cuadrados ordinarios de la relación entre el GC y el DF no necesariamente son insesgados y consistentes (Cameron \& Trivedi, 2009; Greene, 2012), al violarse el supuesto de exogeneidad de las variables independientes, en este caso del GC, se pueden afectar de manera notable las conclusiones de estos estudios. Así, autores como Benjamin E. Hermalin y Michael S. Weisbach (1998, 2003) e Inessa Love (2011) indican que este problema afecta las aseveraciones de diversos estudios en la materia, en vista de que sin un claro vínculo de causalidad entre el GC y el DF, aquellas investigaciones que sugieren a las empresas mejorar sus niveles de gobernanza para lograr optimizar sus resultados financieros se quedarían sin sustento, teniendo en cuenta que sus aseveraciones pueden estar sesgadas al obviar la simultaneidad entre estas variables. En este sentido, la razón para que los errores no sean ortogonales a las diferentes medidas de GC, hecho que pone de manifiesto la condición de endogeneidad, estriba en que en muchos casos se pueden omitir variables correlacionadas con el GC, al igual que se pueden presentar otros problemas relacionados con la causalidad entre el GC y el DF. En el caso de las variables omitidas, no se puede afirmar que los términos de error sean esféricos 
mientras es posible que haya una relación entre el término de error y el GC que se sustenta en la presencia de características no observadas o heterogeneidad no observada de las firmas en este caso (Bhagat \& Bolton, 2008), que es omitida por el análisis de regresión (Baltagi, 2005; Greene, 2012).

Por otro lado, en lo que concierne a la relación de causalidad entre el GC y el DF, no se puede afirmar de forma unánime, según la revisión de literatura realizada por Benjamin E. Hermalin y Michael S. Weisbach (2003) e Inessa Love (2011), que la misma va desde la primera variable hacia la segunda, de hecho se puede plantear una relación de causalidad simultánea $^{21}$. Esta condición indica que al menos una de las variables explicativas, en este caso el GC, se determina simultáneamente con la variable dependiente (DF), haciendo que el término de error del análisis de regresión no sea esférico (Greene, 2012; Wooldridge, 2010).

Teniendo en cuenta lo anterior, a continuación se presentan algunas soluciones que se aprecian en la literatura a partir del estudio de Inessa Love (2011). Esta autora busca ahondar en la relación entre GC y rendimiento, a partir de la revisión de la literatura hasta el momento. Esta relación de causalidad resulta por varias razones. La autora menciona las siguientes: i) empresas que tienen un alto valor en el mercado o mayor rendimiento pueden elegir adoptar mejores prácticas de GC,

21 En este análisis, las firmas con mal desempeño financiero pueden optar por mejorar sus prácticas de gobierno corporativo, por ejemplo, al incrementar la independencia de la junta, como medida para aumentar sus resultados financieros. ii) empresas con un desempeño deficiente toman decisiones que se pueden asociar con un inexistente o mal GC, iii) las firmas podrían adoptar mejores prácticas de GC para enviar al mercado una señal de mejor desempeño en el futuro o para advertir a los gerentes que deben abstenerse de ejecutar prácticas ineficientes, iv) los inversionistas extranjeros o institucionales están más atraídos por empresas que tienen mayor valor y esto conduce a mejores prácticas de GC, y finalmente, v) variables omitidas, como características no observables o datos no disponibles (oportunidades de negocio, riesgos, etc.). La autora expone diversos métodos que buscan corregir esta endogeneidad, a partir de este estudio (tabla 5).

$\mathrm{Al}$ respecto, se pueden mencionar otros ejemplos como el de Sanjai Bhagat y Brian Bolton (2008) que dan cuenta de la existencia de un problema de causalidad simultánea entre el desempeño financiero, el GC, la estructura de propiedad y la estructura de capital. Frente a ello, estos autores lidian con esta situación por medio de un sistema de ecuaciones y el uso de variables instrumentales, mediante la estimación de las relaciones entre esas variables haciendo uso del método de mínimos cuadrados en dos etapas. Por su parte, Ke Li, Lei Lu, Usha R. Mittoo y Zhou Zhang (2015) para un estudio de relación entre la independencia de la junta y el desempeño financiero de las firmas en China exhiben la importancia de considerar el problema de endogeneidad entre esas variables y utilizan los rezagos de la razón de independencia de la junta como instrumento para la estimación de mínimos cuadrados en dos etapas para realizar sus inferencias. 


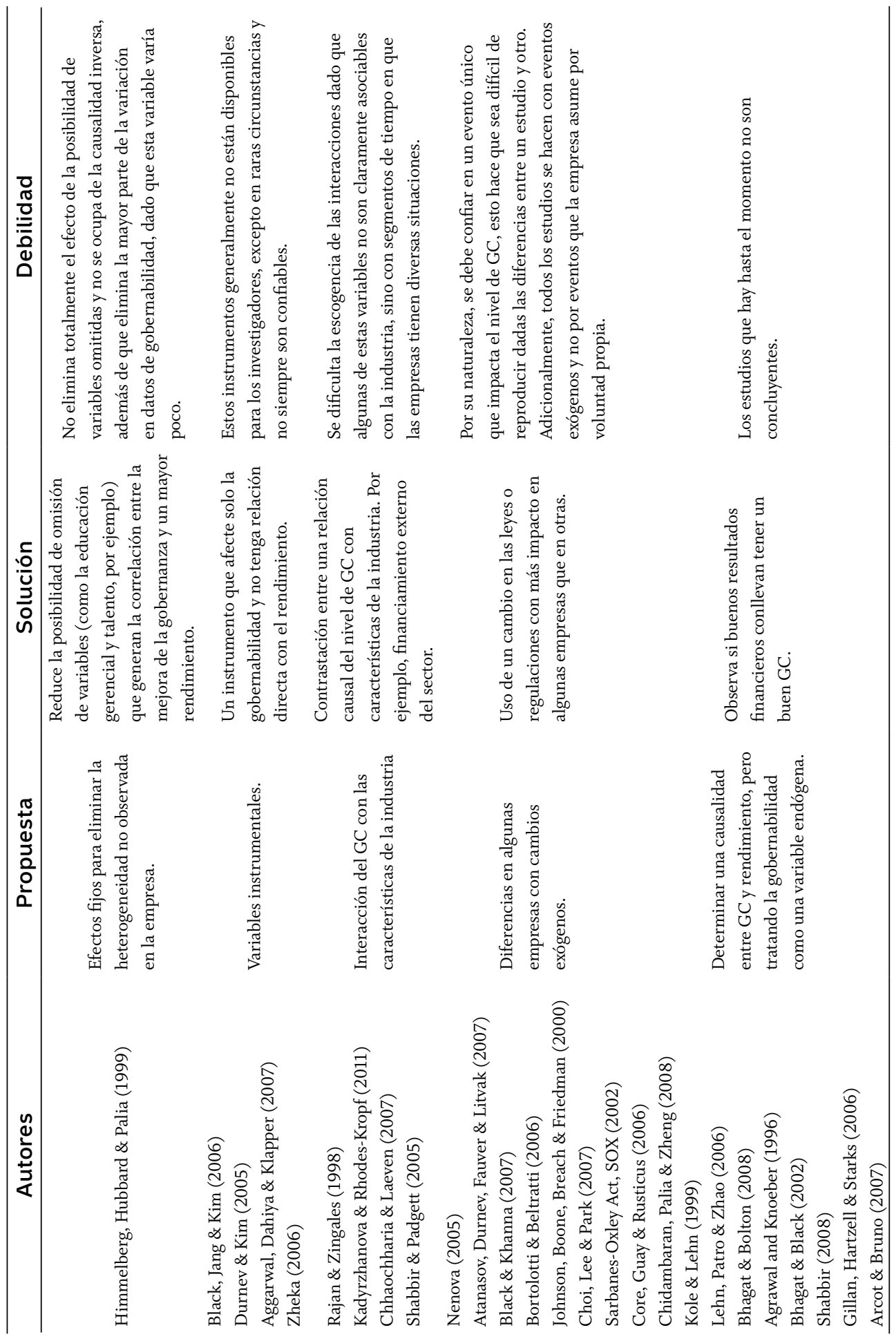


238 / VOL. 17 / NO. 43 / ENERO-JUNIO 2016

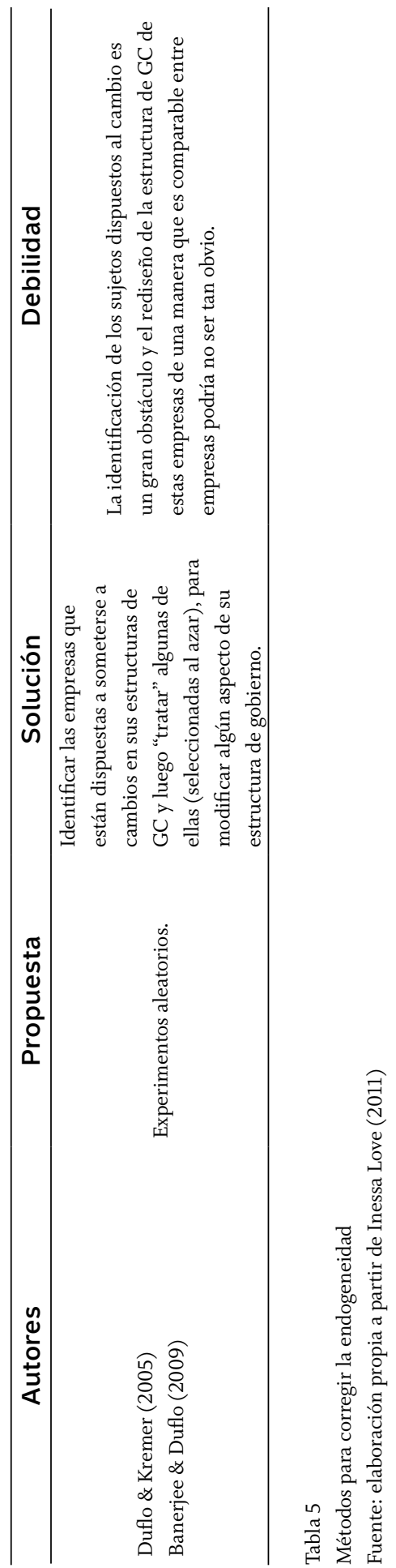


De esta forma, se constata que la endogeneidad es un problema con el que deben lidiar los investigadores dedicados a elaborar estudios empíricos de las prácticas de GC y su efecto en el DF; no obstante, se ha experimentado con nuevas formas de tratamiento de datos que podrían ser útiles a la hora de implementar soluciones a este problema.

\section{Conclusiones}

Las buenas prácticas de GC son un eje del desarrollo empresarial en la medida en que facilitan un mayor dinamismo en la captación de capital vía disminución del riesgo y la toma adecuada de decisiones a la vez que contribuyen con un mayor crecimiento y rentabilidad. Dado este panorama, es fundamental el estudio de las prácticas de GC en las regiones no solo para entender el contexto, sino para contribuir a su desarrollo por medio del impulso de políticas de gobierno o iniciativas de autorregulación.

Por otra parte, en países emergentes, el mejoramiento de prácticas empresariales por la vía de las prácticas de GC podría tener un gran impacto, dada la gran proporción de empresas familiares y pequeñas (Vélez-Montes, HolguínLagos, De La Hoz-Pinzón, Durán-Bobadilla \& Gutiérrez-Ayala, 2008). Lo anterior implica que esas mejoras recaen directamente sobre las familias y el desarrollo de pequeñas empresas. Además, dado el bajo desarrollo de estas prácticas en los países emergentes, al mejorar las políticas asociadas al GC se atrae capital extranjero, lo que permite aumentar las posibilidades de acceso al financiamiento externo.
En Colombia, la investigación en GC, tanto teórica como práctica, está en etapa de maduración. Sin embargo, en las empresas, el GC ha ganado visibilidad en la agenda de discusión del Estado y de los organismos gremiales. Esto implica que las posibilidades de investigación son amplias, aunque suele haber restricción en el acceso a la información empresarial.

La recopilación de las normas presentada en este documento muestra importantes avances en legislación relacionada con el GC en Colombia; en particular, la promulgación de la Ley 964 de 2005 y la revisión del Código País (2014). No obstante, se deben pensar mejoras relacionadas con fortalecer los derechos de los accionistas en especial en temas relacionados con la potestad sobre decisiones corporativas críticas de la firma y trato equitativo, principalmente cuando se presentan reestructuraciones de la empresa. Respecto a la divulgación de información es de suma importancia que la legislatura apunte a que el mercado reconozca la estructura de propiedad de las firmas participantes en el mercado de valores, además de información precisa sobre transacciones con partes relacionadas. Esto con el fin de tener un mercado de capitales más transparente y en consecuencia identificar los posibles conflictos de interés. Además de esto, es importante delimitar una legislación mínima y que las firmas adopten estándares que superen las leyes de manera voluntaria. En este sentido, la exigencia de la adopción de un código de GC por parte de la Superintendencia Financiera y luego el diligenciamiento obligatorio de la encuesta Código País es un paso adelante. Finalmente, las prácticas de GC no deben ser solo una preocupación de empresas participantes del 
mercado de valores, sino que la legislación también debe tocar las empresas cerradas, dado que las prácticas de GC generan valor y mejoran las posibilidades de financiación externa (Del Valle \& Carvajal, 2005); a esta preocupación responde la Guía colombiana de GC para sociedades cerradas $y$ de familia.

En otro sentido, la medición del impacto de las prácticas empresariales se dificulta por numerosas razones. Entre las más importantes se podrían considerar: i) aunque las empresas se pueden clasificar en ciertas categorías por sector o tamaño, la diversidad entre empresas es alta, dado que cada una tiene su propio clima organizacional y formas propias de alcanzar sus objetivos, ii) los datos relacionados con prácticas empresariales suelen ser recogidos por entidades gubernamentales para la medición de fenómenos que no necesariamente están dirigidos al desarrollo y avance de investigación de la región, además de la dificultad de garantizar su adecuado diligenciamiento, iii) la excesiva reserva empresarial, característica de Colombia, dificulta la labor del investigador para la obtención de datos de primera mano, y iv) en los países emergentes, las empresas, al ser en su mayoría familiares, cerradas y pequeñas, no tienen diseñados sistemas de información apropiados; esto implica que incluso si estas quisieran compartir sus prácticas empresariales, el proceso se dificulta.

Además, en el caso de la medición de las variables de GC, la dificultad radica en la ambigüedad de los fenómenos a estudiar, dado que estos surgen a partir de decisiones que se toman en la alta gerencia (junta directiva, comités como el de auditoría o remuneración, y demás), lo que ocasiona que esta información sea de difícil acceso o inestimable. Un ejemplo de esto es la medición de la independencia de la junta directiva, que gran parte de los artículos analizados en este documento intenta hacer.

La creación de valor para las firmas y sus accionistas es el elemento más importante a la hora de implementar prácticas de GC. Esto puede observarse en los estudios aquí analizados, pues en su mayoría miden variables financieras asociadas a la firma o la generación de beneficios económicos a los accionistas. En general, los modelos econométricos utilizados elaboran un índice de GC o identifican una variable que se aproxime al nivel de calidad GC y lo asocian con variables relacionadas con el desempeño financiero como EBIT, ROA o la $\mathrm{Q}$ de Tobin, aunque algunos documentos relacionan el GC con tipos de control de las firmas (familiar, cerrada, abierta, y demás) o el origen legal del país donde opera la firma, siendo este tipo de estudios la minoría.

Adicionalmente, la mayoría de las investigaciones resalta el contexto legal de las firmas como determinante en el nivel de la calidad de las prácticas de GC. Esta idea no solo se desarrolla a partir de las normas obligatorias, sino de la necesidad de la autorregulación de las firmas. A partir de esto se concluye que este tipo de estudios debe encaminarse hacia el análisis del contexto general en el que están inmersas las empresas objeto de estudio. Esto muestra la relevancia de líneas de investigación que giren en torno al ambiente institucional de las firmas.

Por otro lado, la visión de la firma y su objetivo de maximización alternativo, planteada por Michel Aglietta y Antoine Rebérioux (2005), 
presenta interesantes desafíos, tanto en la definición de las variables de interés como en la estructuración de las pruebas empíricas. Si el modelo de codeterminación particular de algunas economías de Europa Occidental permite la medición del valor desde esta óptica, seguramente será fuente de intensas discusiones y es una agenda abierta para los investigadores.

Si bien la teoría de la agencia se configura como el eje para el desarrollo y análisis de las prácticas de GC, se hace necesario reconocer ejes teóricos alternativos que permitan abordar esta temática al tener en cuenta otro tipo de fenómenos más allá de la premisa que supone la separación entre la propiedad y el control. Si bien la teoría de stewardship es vista como un caso especial de la teoría de la agencia, esta abre un nuevo enlace de posibilidades en el cual los individuos son vistos más allá de sus intereses propios. Esto implica que las prácticas de GC deben ser abordadas desde un enfoque multiteórico que permita un mayor entendimiento de los fenómenos y comportamientos sociales que se presentan a raíz de las dinámicas empresariales.

Este documento abordó el enfoque de la teoría del servidor (stewardship) que permite analizar a los gestores desde un punto de vista contrario al estudiado en la corriente principal de los estudios de gestión, que ve al gestor como alguien que busca su propio beneficio por encima de cualquier cosa. En este sentido surge la pregunta: ¿Son los gestores individuos absolutamente racionales que buscan su propio beneficio ante cualquier situación? Y en caso de que la respuesta sea positiva, surge una segunda inquietud: ¿Siempre han sido así?
Teniendo en cuenta estas preguntas, es trascendental pensar si los ejes teóricos planteados desde la academia han tenido una repercusión en las dinámicas de gestión. Es decir, en qué medida los supuestos de egoísmo y oportunismo impartidos a los profesionales de la gestión desde las escuelas de gestión han hecho que estos actúen bajo estos preceptos. Los mecanismos de gestión aquí analizados, en su mayoría, están diseñados para controlar a individuos que de tener la oportunidad de sacar provecho lo harían sin ningún escrúpulo. Así, se deja abierta una línea de pensamiento que lleve a repensar al sujeto y su papel dentro de la organización, a partir de nuevos enfoques teóricos que permitan ir más allá de los supuestos establecidos.

\section{Referencias}

Adams, Renée B.; Hermalin, Benjamin E. \& Weisbach, Michael S. (2010). The Role of Boards of Directors in Corporate Governance: A Conceptual Framework a Survey. Journal of Economic Literature, 48 (1), 58-107. Disponible en: https://fisher.osu. edu/ weisbach.2/AdamsHWJEL2010.pdf Aggarwal, Reena; Dahiya, Sandeep \& Klapper, Leora (2007). ADR Holdings of U.S.-Based Emerging Market Funds. Journal of Banking and Finance, 31 (6), 1649-1667. Disponible en: http://faculty.msb.edu/aggarwal/adrs_ dec1104.pdf

Aglietta, Michel \& Rebérioux, Antoine (2005). Corporate Governance Adrift: A Critique of Shareholder Value. Cheltenham, Northampton: The Saint-Gobain Centre for Economic Studies Series. 
Agrawal, Anup \& Knoeber, Charles R. (1996).

Firm Performance and Mechanisms to Control Agency Problems between Managers and Shareholders. The Journal of Financial and Quantitative Analysis, 31 (3), 377-397. Disponible en: http://www.bama. ua.edu/ aagrawal/jfqa96.pdf

Anderson, Ronald C.; Mansi, Sattar A. \& Reeb, David M. (2004). Board Characteristics, Accounting Report Integrity, and the Cost of Debt. Journal of Accounting and Economics, 37, 315-342. Disponible en: http://citeseerx.ist.psu.edu/viewdoc/down load?doi=10.1.1.468.2023\&rep= rep1\&typ $\mathrm{e}=\mathrm{pdf}$

Arbeláez, María Angélica; Zuluaga, Sandra \& Guerra, María Lucía (2002). El mercado de capitales colombiano en los noventa y las firmas comisionistas de bolsa. Bogotá: Fedesarrollo, Alfaomega

Arcot, Sridhar \& Bruno, Valentina (2007). One size does not fit all, after all: Evidence from Corporate Governance. Journal of Empirical Legal Studies, 4 (4), 1041-1057.

Atanasov, Vladimir; Durnev, Artyom; Fauver, Larry \& Litvak, Kate (2007). Preemptive Rights and Other Anti-Dilution Protections around the World. Working Paper.

Disponible en: https://law.utexas.edu/ wp-content/uploads/sites/25/atanasov_ preemptive_rights.pdf

Baltagi, Badi H. (2005). Econometric Analysis of Panel Data. $3^{\text {rd }}$ ed. New York: John Wiley \& Sons.

Banerjee, Abhijit \& Duflo, Esther (2009) The Experimental Approach to Development Economics. Annual Review of Economics, 1,
151-178. Disponible en: http://economics. mit.edu/files/3158

Baysinger, Barry D. \& Butler, Henry N. (1985). Corporate Governance and the Board of Directors: Performance Effects of Changes in Board Composition. Journal of Law, Economics \& Organization, 1 (1), 101-124.

Benavides-Franco, Julián (2005).

Concentración de la propiedad

y desempeño contable: el caso

latinoamericano. Borradores de Economía y Finanzas, 4, 1-35. Disponible en: https:// www.icesi.edu.co/departamentos/ economia/publicaciones/docs/BORRAECO/ Borrador\%20de\%20Economia\%204.pdf Benavides-Franco, Julián \& Mongrut-Montalván, Samuel (2010). Governance Codes: Facts or Fictions? A Study of Governance Codes in Colombia. Estudios Gerenciales, 26 (117), 85-102. Disponible en: http://www. redalyc.org/pdf/212/21218551004.pdf

Benavides-Franco, Julián; Mongrut-Montalván, Samuel \& González-Velasco, Mónica (2012). Family Ties, Do They Matter ? Family Ownership and Firm Performance in Peru. Corporate Ownership and Control, 9 (4), 96-107.

Berle, Adolf A. \& Means, Gardiner C. ([1932] 1991). The Modern Corporation and Private Property. New Brunswich, London: Transaction Publishers.

Bhagat, Sanjai \& Black, Bernard S. (1999). The Uncertain Relationship between Board Composition and Firm Performance. The Business Lawyer, 54, 921-963. Disponible en http://papers.ssrn.com/sol3/papers. cfm?abstract_id=11417 
Bhagat, Sanjai \& Bolton, Brian (2008).

Corporate Governance and Firm

Performance. Journal of Corporate Finance, 14 (3), 257-273. Disponible en: http:// leeds-faculty.colorado.edu/bhagat/ GovernancePerformance-JCF-June2008. pdf, doi:10.1016/j.jcorpfin.2008.03.006

Bhagat, Sanjai \& Black, Bernard S. (2002). The Non-Correlation between Board Independence and Long-Term Firm Performance. Stanford Law and Economics Olin Working Paper 185. Disponible en: http://papers.ssrn.com/ sol3/papers.cfm?abstract_id=133808\#\#

Black, Bernard S.; Jang, Hasung \& Kim, Woochan (2006). Does Corporate Governance Predict Firms' Market Values? Evidence from Korea. Journal of Law, Economics, and Organization, 22 (2), 366-413. Disponible en: http://papers.ssrn.com/sol3/papers. cfm?abstract_id $=311275$

Black, Bernard S. \& Khanna, Vikramaditya S. (2007). Can Corporate Governance Reforms Increase Firm Market Values? Event Study Evidence from India. Journal of Empirical Legal Studies, 4, 749-796. Disponible en: http://fic.wharton.upenn. edu/fic/india/21\%20black\%20khanna.pdf

Bortolotti, Bernardo \& Beltratti, Andrea (2006). The Nontradable Share Reform in the Chinese Stock Market. Nota di lavoro 131.2006, Bocconi University. Disponible en: http://www.feem.it/userfiles/attach/ Publication/NDL2006/NDL2006-131.pdf Boyer, Robert (2007). Crisis y regímenes de crecimiento: una introducción a la teoría de la regulación. Buenos Aires: Miño y Dávila, Centro de Estudios e Investigaciones Labo- rales. Programa de Investigaciones Económicas sobre Tecnología, Trabajo y Empleo, CEIL-PIETTE, Trabajo y Sociedad.

Brickley, James A.; Coles, Jeffrey \& Terry, Rory L. (1994). Outside Directors and the Adoption of Poison Pills. Journal of Financial Economics, 35 (3), 371-390.

Brown, Lawrence D. \& Caylor, Marcus L. (2004a). Corporate Governance and Firm Performance. Disponible en: http:// www.whartonwrds.com/wp-content/ uploads/2016/05/Sept-23-CorporateGovernance-and-Firm-Performance.pdf Brown, Lawrence D. \& Caylor, Marcus L. (2004b). Corporate Governance Study: The Correlation between Corporate Governance and Company Performance. Institutional Shareholder Services. Disponible en: http://boardoptions.com/ issscoresandshareholdervalue.pdf

Caers, Ralf; Bois, Cindy du; Jegers, Marc; Gieter, Sara de; Schepers, Catherine \& Pepermans, Roland (2006). Principal-Agent Relationships on the Stewardship-Agency Axis. Nonprofit Management \& Leadership, 17 (1), 25-45. Disponible en: http://citeseerx. ist.psu.edu/viewdoc/download?doi=10.1.1.5 84.2966\&rep $=$ rep1\&type $=$ pdf

Cameron, A. Colin \& Trivedi, Pravin K. (2009). Microeconometrics Using Stata. College Station, Texas: Stata Press.

Chhaochharia, Vidhi \& Laeven, Luc (2007). Corporate Governance, Norms and Practices. European Corporate Governance Institute, ECGI - Finance Working Paper, 165/2007. Disponible en: http://papers.ssrn.com/sol3/ papers.cfm?abstract_id $=965733$ 
Chen, En-Te \& Nowland, John (2010). Optimal Board Monitoring in Family-owned Companies: Evidence from Asia. Corporate Governance: An International Review, 18 (1), 3-17.

Chidambaran, N. K.; Palia, Darius \& Zheng, Yudan (2008). Corporate Governance and Firm Performance: Evidence from Large Governance Changes. Disponible en: http://papers.ssrn. com/sol3/papers.cfm?abstract_id=1108497

Chile, Ley 19705 de 2000, que regula las ofertas públicas de adquisición de acciones (OPA) y establece régimen de gobiernos corporativos. Disponible en: http://www.leychile.cl/ Navegar?idLey $=19705$

Choi, Jung Yong; Lee, Dong Wook \& Park, Kyung-Suh (2007). Corporate Governance and Firm Value: Endogeneity-Free Evidence from Korea. Paper presented at the International Research Conference on Corporate Governance in Emerging Markets, Istanbul, 15-18 November. Disponible en: http://www.ifc.org/wps/wcm/connect/ c4b5a90048a7e54ba0e7e76060ad5911/ Lee\%252C\%2BChoi\%252C\%2BPark.pdf? $\mathrm{MOD}=\mathrm{AJPERES} \&$ ContentCache $=\mathrm{NONE}$ Claessens, Stijn; Djankov, Simeon; Fan, Joseph P. \& Lang, Larry H. (2002). Disentangling the Incentive and Entrenchment Effects of Large Shareholdings. The Journal of Finance, 57 (6), 2741-2771.

Claessens, Stijn; Klingebiel, Daniela \& Lubrano, Mike (2000). Corporate Governance Reform Issues in the Brazilian Equity Markets. Washington: World Bank, Working Paper 27056. Disponible en: http://documents.worldbank.org/ curated/en/726601468770349987/ pdf/270560Brazil0equity0market.pdf Claessens, Stijn \& Yurtoglu, Burcin (2013). Corporate Governance in Emerging Markets: A Survey. Emerging Market Review, 15 (C), 1-33.

Coase, Ronald H. (1937). The Nature of the Firm. Economica, New Series, 4 (16), 386405. Disponible en: http://www.colorado. edu/ibs/es/alston/econ4504/readings/ The $\% 20$ Nature $\% 20$ of $\% 20$ the $\% 20$ Firm $\% 20$ by\%20Coase.pdf

Colombia (1971). Decreto 410 de 1971, por el cual se expide el Código de Comercio. Diario Oficial, 33.339, 16 de junio de 1971. Disponible en: http://www. secretariasenado.gov.co/senado/basedoc/ codigo_comercio.html

Colombia (1995). Ley 222 de 1995, por la cual se modifica el Libro II del Código de Comercio, se expide un nuevo régimen de procesos concursales y se dictan otras disposiciones. Diario Oficial, 42.156, 20 de diciembre de 1995. Disponible en: http:// www.secretariasenado.gov.co/senado/ basedoc/ley_0222_1995.html

Colombia (1998). Ley 446 de 1998, por la cual se adoptan como legislación permanente algunas normas del Decreto 2651 de 1991, se modifican algunas del Código de Procedimiento Civil, se derogan otras de la Ley 23 de 1991 y del Decreto 2279 de 1989 , se modifican y expiden normas del Código Contencioso Administrativo y se dictan otras disposiciones sobre descongestión, eficiencia y acceso a la justicia. Diario Oficial, 43.335, 8 de julio de 1998. Disponible en: 
http://www.secretariasenado.gov.co/senado/ basedoc/ley_0446_1998.html

Colombia (2005). Ley 964 de 2005, por la cual se dictan normas generales y se señalan en ellas los objetivos y criterios a los cuales debe sujetarse el Gobierno Nacional para regular las actividades de manejo, aprovechamiento e inversión de recursos captados del público que se efectúen mediante valores y se dictan otras disposiciones. Diario Oficial, 45.963, 8 de julio de 2005. Disponible en: http://www.secretariasenado.gov.co/ senado/basedoc/ley_0964_2005.html

Colombia, Superintendencia de Sociedades, Cámara de Comercio de Bogotá \& Confederación Colombiana de Cámaras de Comercio, Confecámaras (2009). Guía colombiana de gobierno corporativo para sociedades cerradas y de familia. Disponible en: http://www.confecamaras.org.co/ phocadownload/GobiernoCorporativo/ guiacolombiana.pdf

Colombia, Superintendencia de Valores, hoy Superintendencia Financiera (2001). Resolución 275, 23 de mayo de 2001, por la cual se establecen los requisitos que deben acreditar las personas jurídicas públicas y privadas que pretendan ser destinatarias de la inversión de recursos de los fondos de pensiones. Disponible en: https://www. superfinanciera.gov.co/jsp/loader.jsf?lServi cio $=$ Publicaciones\&lTipo $=$ publicaciones\&l Funcion $=$ loadContenidoPublicacion $\& i d=8$ $21 \&$ dPrint $=1$

Colombia, Superintendencia Financiera (2007). Circular externa 028, presentación del nuevo Código País y adopción del
Reporte de implementación de mejores prácticas corporativas, 30 de septiembre de 2007. Disponible en: https://www. superfinanciera.gov.co/descargas?com =inst itucional\&name $=$ pubFile1010034\&downlo adname $=$ ce028_14.docx.

Colombia, Superintendencia Financiera (2007). Circular externa 056, modificación de la Circular Externa 028 de 2007, 2 de noviembre de 2007. Disponible en: https:// www.superfinanciera.gov.co/SFCant/ NormativaFinanciera/Archivos/ce056_07. rtf.

Colombia, Superintendencia Financiera (2007). Código de mejores prácticas corporativas, Colombia. Bogotá: Superintendencia Financiera de Colombia. Disponible en: https://www. superfinanciera.gov.co/SFCant/Codigopais/ textos/codigopias.pdf

Colombia, Superintendencia Financiera (2014). Código País de Colombia, Código de Mejores Prácticas Corporativas. Disponible en: https://www.superfinanciera.gov.co/jsp/ loader.jsf?lServicio $=$ Publicaciones\&lTipo $=$ publicaciones\&lFuncion $=$ loadContenidoPu blicacion\&id $=10083770$

Colombia, Superintendencia Financiera (2014). Presentación del Código País de Gobierno Corporativo para Emisores de Valores. Bogotá: Superintendencia Financiera de Colombia. Disponible en: https://www. superfinanciera.gov.co/jsp/loader.jsf?lSer vicio $=$ Publicaciones\&lTipo $=$ publicacione s\&lFuncion=loadContenidoPublicacion\& id $=10083770$ 
Committee on the Financial Aspects of Corporate Governance \& Cadbury, Adrian (1992). Cadbury Report, Financial Aspects of Corporate Governance. Disponible en: http://www.ecgi.org/codes/documents/ cadbury.pdf

Core, John E.; Holthausen, Robert W. \& Larcker, David F. (1999). Corporate Governance, Chief Executive Compensation, and Firm Performance. Journal of Financial Economics, 51, 371406. Disponible en: https://fisher.osu. edu/ young.53/Core-Holthausen-Larcker. pdf

Core, John E.; Guay, Wayne R. \& Rusticus, Tjomme O. (2006). Does Weak Governance Cause Weak Stock Returns? An Examination of Firm Operating Performance and Investors' Expectations. The Journal of Finance, 61 (2), 655-687.

Davis, James H.; Schoorman, F. David \& Donaldson, Lex (1997). Toward a Stewardship Theory of Management. Academy of Management Journal, 22 (1), 20-47.

Denis, Diane K. \& McConnell, John J. (2003) International Corporate Governance. European Corporate Governance Institute, ECGI - Finance Working Paper, 05/2003; Tuck School of Business at Dartmouth Tuck-JQFA Contemporary Corporate Governance Issues II Conference.

Disponible en: http://papers.ssrn.com/sol3/ papers.cfm?abstract_id=320121

Djankov, Simeon; La Porta, Rafael; Lopezde-Silanes, Florencio \& Shleifer, Andrei (2008). The Law and Economics of SelfDealing. Journal of Financial Economics,
88 (3), 430-465. Disponible en: http:// www.doingbusiness.org/ /media/ FPDKM/Doing\%20Business/Documents/ Methodology/Supporting-Papers/DBMethodology-Law-and-Economicsof-Self-Dealing.pdf, doi:10.1016/j. jfineco.2007.02.007

Donaldson, Lex (1990). The Ethereal Hand: Organizational Economics and Management Theory. Academy of Management Review, 15 (3), 369-381. doi:10.5465/ AMR.1990.4308806

Donaldson, Lex \& Davis, James H. (1991). Stewardship Theory or Agency Theory: CEO Governance and Shareholder Returns. Australian Journal of Management, 1 (16), 49-64. Disponible en: http://citeseerx.ist. psu.edu/viewdoc/download?doi=10.1.1.199. 6439\&rep $=$ rep1\&type $=$ pdf

Duflo, Esther \& Kremer, Michael (2005). Use of Randomization in the Evaluation of Development Effectiveness. En George Pitman, Osvaldo Feinstein \& Gregory Ingram (eds.). Evaluating Development Effectiveness. World Bank Series on Evaluation and Development, volume 7. New Brunswick, New Jersey: Transaction Publishers. Texto disponible en: http:// economics.mit.edu/files/765

Durnev, Artyom \& Kim, E. Han (2005). To Steal or Not to Steal: Firm Attributes, Legal Environment, and Valuation. The Journal of Finance, 60 (3), 1461-1493. Disponible en: https://deepblue.lib.umich.edu/ bitstream/handle/2027.42/72566/j.15406261.2005.00767.x.pdf?sequence $=1 \&$ isAll owed $=\mathrm{y}$ 
Easterbrook, Frank H. (1984). Two AgencyCost Explanations of Dividends. American Economic Review, 74 (4), 650-659.

Estados Unidos (2002). Sarbanes-Oxley Act, SOX, Public Law 107-204, July 30, 2002, 116 Stat. 745. Disponible en: https://www. sec.gov/about/laws/soa2002.pdf

Fama, Eugene \& French, Kenneth R. (2002). The Equity Premium. The Journal of Finance, 57 (2), 637-659.

Fama, Eugene \& Jensen, Michael C. (1983). Separation of Ownership and Control. Journal of Law and Economics, 26 (2), 301325. Disponible en: http://www.wiwi.unibonn.de/kraehmer/Lehre/SeminarSS09/ Papiere/Fama_Jensen_Separation_ ownership_control.pdf

Fernández-Aguado, Javier (2006). Fundamentos de la organización de empresas: breve historia del management. Madrid: Narcea S.A. de Ediciones.

Fox, Mark A. \& Hamilton, Robert T. (1994). Ownership and Diversification: Agency Theory or Stewardship Theory. Journal of Management Studies, 31 (1), 69-81. Disponible en: http://down.cenet.org.cn/ upfile/36/20078161644161.pdf

Franco, Andrés \& Lombaerde, Philippe André Achiel de (2000). Las empresas multinacionales latinoamericanas. El caso de la inversión colombiana directa en Ecuador, México, Perú y Venezuela. Bogotá: Tercer Mundo Editores.

Frankel, Richard; Johnson, Marilyn \& Nelson, Karen (2002). The Relation between Auditors' Fees for Non-Audit Services and Earnings Management. Accounting Review, 77 (1), 71-105.
Gabrielsson, Jonas \& Huse, Morten (2004). Context, Behavior, and Evolution: Challenges in Research on Boards and Governance. International Studies of Management \& Organization, 34 (2), 11-36.

Garay, Urbi; González, Germán; González, Maximiliano \& Hernández, Yelhis (2006). Índice de buen gobierno corporativo $y$ desempeño financiero en la Bolsa de Valores de Caracas. Caracas: Instituto de Estudios Superiores en Administración, IESA, Estudios IESA, 24. Disponible en: http:// servicios.iesa.edu.ve/Portal/EstudiosIESA/ Indicegobiernocorporativo.pdf

Gillan, Stuart; Hartzell, Jay C. \& Starks, Laura T. (2006). Tradeoffs in Corporate Governance: Evidence from Board Structures and Charter Provisions. Disponible en: http:// papers.ssrn.com/sol3/papers.cfm?abstract_ id $=917544$

Giovannini, Renato (2010). Corporate Governance, Family Ownership and Performance. Journal of Management and Governance, 14 (2), 145-166. doi:10.1007/s10997-0099093-x

Gompers, Paul A.; Ishii, Joy L. \& Metrick, Andrew (2003). Corporate Governance and Equity Prices. Quarterly Journal of Economics, 118 (1), 107-155. Disponible en: http:// papers.ssrn.com/sol3/papers.cfm?abstract_ id $=278920$

González, Maximiliano; Guzmán, Alexander; Pombo, Carlos \& Trujillo, María Andrea (2012). Family Firms and Financial Performance: The Cost of Growing. Emerging Markets Review, 13 (4), 629-649. 
Disponible en: http://papers.ssrn.com/sol3/ papers.cfm?abstract_id=1639157

González, Maximiliano; Guzmán, Alexander; Pombo, Carlos \& Trujillo, María Andrea (2015). The Role of Family Involvement on CEO Turnover: Evidence from Colombian Family Firms. Corporate Governance: An International Review, 23 (3), 266-284.

Grajales-Quintero, Jhonny; Cuevas-Mejía, John Jairo \& Usme-Suárez, Wilson Alexis (2013). Balance de las publicaciones sobre IFRS en dos revistas colombianas. Cuadernos de Contabilidad, 14 (spe36), 1183-1207. Disponible en: http:// cuadernosdecontabilidad.javeriana.edu.co/ vol14_n_36/vol14_36_11.pdf

Grant, Patricia \& McGhee, Peter (2014). Corporate Governance Reform: Character-Building Structures. Business Ethics: A European Review, 23 (2), 125-138. doi:10.1111/ beer. 12043

Greene, William H. (2012). Econometric Analysis. 7th ed. Boston, London: Pearson Education.

Grossman, Sanford J. \& Hart, Oliver D. (1986). The Costs and Benefits of Ownership: A Theory of Vertical and Lateral Integration. Journal of Political Economy, 94 (4), 691-719. Gruszczynski, Marek (2006). Corporate Governance and Financial Performance of Companies in Poland. International Advances in Economic Research, 12 (2), 1-10.

Guest, Paul M. (2009). The Impact of Board Size on Firm Performance: Evidence from the UK. The European Journal of Finance, 15 (4), 385-404.
Gutiérrez, Luis Hernando \& Pombo, Carlos (2007). Corporate Governance and Firm Valuation in Colombia. En Alberto Chong \& Florencio López de Silanes (eds.). Investor Protection and Corporate Governance: Firm-Level Evidence across Latin America, 353-396. Washington: The Inter-American Development Bank, World Bank, Stanford University Press.

Gutiérrez, Luis Hernando; Pombo, Carlos \& Taborda, Rodrigo (2008). Ownership and Control in Colombian Corporations. The Quarterly Review of Economics and Finance, 48 (1), 22-47. Texto disponible en: http:// www.banrep.gov.co/sites/default/files/ eventos/archivos/BI66Carlos_Pombo.pdf Haniffa, Roszaini \& Hudaib, Mohammad (2006). Corporate Governance Structure and Performance of Malaysian Listed Companies. Journal of Business Finance \& Accounting, 33 (7 8), 1034-1062.

Hart, Oliver (1995). Corporate Governance: Some Theory and Implications. Economic Journal, 105 (430), 678-689. Disponible en: http://www.ppge.ufrgs.br/giacomo/ arquivos/gov-corp/hart-1995.pdf

Hassan, Rohail; Marimuthu, Maran \& Johl, Satirenjit Kaur (2015). Diversity, Corporate Governance and Implication on Firm Financial Performance. Global Business and Management Research: An International Journal, 7 (2), 28-36. Disponible en: https:// www.academia.edu/12826470/Diversity_ Corporate_Governance_and_Implication_ on_Firm_Financial_Performance

Hermalin, Benjamin E. \& Weisbach, Michael S. (1991). The Effects of Board Composition 
GOBIERNO CORPORATIVO Y DESEMPEÑo FINANCIERO / N. ESCOBAR, J. BENAVIDES, H. PERAFÁN / 249

and Direct Incentives on Firm Performance. Financial Management, 20 (4), 101-112. Hermalin, Benjamin E. \& Weisbach, Michael S. (1998). Endogenously Chosen Boards of Directors and Their Monitoring of the CEO. The American Economic Review, 88 (1), 96118. doi:10.2307/116820

Hermalin, Benjamin E. \& Weisbach, Michael S. (2003). Boards of Directors As An Endogenously Determined Institution: A Survey of The Economic Literature. Economic Policy Review, 9 (1), 7-26. Disponible en: http:// papers.ssrn.com/sol3/papers.cfm?abstract_ id=794804, doi:10.2139/ssrn.233111

Himmelberg, Charles P.; Hubbard, R. Glenn \& Palia, Darius (1999). Understanding the Determinants of Managerial Ownership and the Link between Ownership and Performance. Journal of Financial Economics, 53 (1999) 353-384. Disponible en: https://www0.gsb.columbia.edu/ faculty/ghubbard/Articles\%20for\%20 Web\%20Site/Understanding\%20the\%20 Determinants\%20of\%20Managerial\%20 Ownership\%20and\%20t.pdf

Jara-Pinilla, Natalia (2014). Gobierno corporativo: una revisión. Santiago de Chile: Seminario para optar al título de Ingeniero Comercial, Mención Administración de Empresas. Universidad de Chile. Disponible en: http://repositorio.uchile.cl/bitstream/ handle/2250/115223/NATALIA_JARA. pdf? sequence $=1 \&$ isAllowed $=y$ Jensen, Michael C. (1993). The Modern Industrial Revolution, Exit, and the Failure of Internal Control Systems. Journal of Finance, 48 (3), 831-880. Disponible en: https://fdp.hse.ru/data/084/482/1225/ Sept\%2016\%20The\%20Modern\%20 Industrial\%20Revolution..ure\%20of\%20 Internal\%20Control\%20Systems.pdf Jensen, M. \& Meckling, W. (1976). Theory of the Firm: Managerial Behavior, Agency Costs and Ownership Structure. Journal of Financial Economics, 3 (4), 305-360. Disponible en: http://uclafinance.typepad.com/ main/files/jensen_76.pdf

Johnson, Simon; Boone, Peter; Breach, Alasdair $\&$ Friedman, Eric (2000). Corporate Governance in the Asian Financial Crisis. Journal of Financial Economics, 58, 141-186. Disponible en: http://citeseerx.ist.psu.edu/viewdoc/ download?doi=10.1.1.200.2235\&rep=rep1 \&type $=$ pdf

Jong, Abe de; DeJong, Douglas V.; Mertens, Gerard \& Wasley, Charles E. (2005). The Role of Self-Regulation in Corporate Governance: Evidence and Implications from The Netherlands. Journal of Corporate Finance, 11 (3), 473-503.

Kadyrzhanova, Dalida \& Rhodes-Kropf, Matthew (2011). Concentrating on Governance. The Journal of Finance, 66 (5), 1649-1685. Presented at First Academic conference on Corporate Governance Research, presented at Harvard University, presented at University of Pittsburgh. Disponible en: http://papers.ssrn.com/sol3/papers.cfm?abstract_id $=891418$

Kallifatides, Markus; Nachemson-Ekwall, Sophie \& Sjöstrand, Sven-Erik (2010). Corporate Governance in Modern Financial Capitalism: Old Mutual's Hostile Takeover of Skandia. Cheltemham: Edward Elgar. 
Kim, Youngok \& Gao, Fei Yi (2013). Does

Family Involvement Increase Business Performance? Family-Longevity Goals' Moderating Role in Chinese Family Firms. Journal of Business Research, 66 (2), 265-274. doi:10.1016/j.jbusres.2012.08.018

Klapper, Leora F.; Laeven, Luc \& Love, Inessa (2005). What Drives Corporate Governance Reform? Firm-Level Evidence from Eastern Europe. World Bank Policy Research Working Paper 3600. Disponible en: http:// documents.banquemondiale.org/curated/ fr/813551468299116185/pdf/wps3600.pdf

Klapper, Leora F. \& Love, Inessa (2004).

Corporate Governance, Investor Protection, and Performance in Emerging Markets. Journal of Corporate Finance, 10 (5), 703728. Disponible en: http://isiarticles.com/ bundles/Article/pre/pdf/11398.pdf

Klein, April (2002). Audit Committee, Board of Director Characteristics, and Earnings Management. Journal of Accounting and Economics, 33 (3), 375-400.

Kole, Stacey R. \& Lehn, Kenneth M. (1999).

Deregulation and the Adaptation of Governance Structure: the Case of the U.S. Airline Industry. Journal of Financial Economics, 52, 79-117. Disponible en: http://down.cenet.org.cn/ upfile/36/200581310531137.pdf

Krafft, Jackie; Qu, Yiping; Quatraro, Francesco \& Ravix, Jacques-Laurent (2014). Corporate Governance, Value and Performance of Firms: New Empirical Results on Convergence from a Large International Database. Industrial and Corporate Change, Oxford University Press, 23 (2), 361-397.
Kraus, Alan \& Litzenberger, Robert H. (1973). A State-Preference Model of Optimal Financial Leverage. Journal of Finance, 28 (4), 911-922.

Langebaek, Andrés \& Ortiz, Jaime Eduardo (2007). Q de Tobin y gobierno corporativo de las empresas listadas en bolsa. Borradores de Economía, 447, 1-37. Disponible en: http://www.banrep.gov.co/docum/ftp/ borra447.pdf

Leal, Ricardo P. C. \& Carvalhal da Silva, André L. (2005). Corporate Governance and Value in Brazil (and in Chile). Washington: InterAmerican Development Bank, Latin American Research Network, Research Network Working paper R-514. Disponible en http:// www.istfin.eco.usi.ch/r_leal.pdf

Lee, Peggy M. \& O'Neill, Hugh M. (2003). Ownership Structures and R \& D Investments of U. S. and Japanese Firms: Agency and Stewardship Perspectives. Academy of Management Journal, 46 (2), 212-225. doi:10.2307/30040615

Lefort, Fernando (2003). Gobierno corporativo: ¿qué es? y ¿cómo andamos por casa? Cuadernos de Economía, 40 (120), 207-237. Disponible en: http://www.scielo. cl/scielo.php?script=sci_arttext\&pid $=$ S0717-68212003012000002

Lehn, Kenneth; Patro, Sukesh \& Zhao, Mengxin (2006). Governance, Indexes and Valuation: Which Causes Which? University of Pittsburgh, Working Paper. Disponible en: https://www. ualberta.ca/business/en/Faculty $\% 20$ Members/FinanceandStatisticalAnalysis/ MengxinZhao/ /media/ 
GOBIERNO CORPORATIVO Y DESEMPEÑO FINANCIERO / N. ESCOBAR, J. BENAVIDES, H. PERAFÁN / 251

business/FacultyAndStaff/FSA/

MengxinZhao/Documents/

GovernanceIndexesAndValuation.pdf

Li, Ke; Lu, Lei; Mittoo, Usha R. \& Zhang, Zhou (2015). Board Independence, Ownership Concentration and Corporate Performance - Chinese Evidence. International Review of Financial Analysis, 41 (C), 162-175. doi:10.1016/j.irfa.2015.05.024

Lins, Karl V. (2003). Equity Ownership and Firm Value in Emerging Markets. Journal of Financial and Quantitative Analysis, 38 (1), 159-184.

Lipton, Martin \& Lorsch, Jay W. (1992). A Modest Proposal for Improved Corporate Governance. Business Lawyer, 48 (1), 59-77

Love, Inessa (2011). Corporate Governance and Performance around the World: What We Know and What We Don't. World Bank Research Observer, 26 (1), 42-70. Disponible en: http://documentos.bancomundial.org/ curated/es/118271468331761295/pdf/77005 0JRN0wbro0Box0377291B00PUBLIC0.pdf Morgan Stanley Capital International, MSCI (s.f.). All Country World Index \& Frontier Market Index, MSCI ACWI \& Frontier Index. Disponible en: https://www.msci.com/ indexes

Muth, Melinda M. \& Donaldson, Lex (1998). Stewardship Theory and Board Structure: A Contingency Approach. Scholarly Research and Theory Papers, 6 (1), 5-28. Disponible en: http://down.cenet.org.cn/ upfile/47/2005105194618190.pdf

Nenova, Tatiana (2005). Control Values and Changes in Corporate Law in Brazil. Latin
American Business Review, 6, 1-37. http://

dx.doi.org/10.1300/J140v06n03_01

Netherlands, Peters Committee, Monitoring Commissie Corporate Governance Code $(1997,2003)$. Corporate Governance in the Netherlands, the Forty Recommendations' report; Dutch Corporate Governance Code. Disponible en: http://www. commissiecorporategovernance.nl/dutchcorporate-governance-code, http://www. ecgi.org/codes/documents/nl-peters_report. pdf

Nicholson, Gavin J. \& Kiel, Geoffrey C. (2007). Can Directors Impact Performance? A Case Based Test of Three Theories of Corporate Governance. Corporate Governance, An International Review, 15 (4), 585-609.

Oman, Charles; Fries, Steven \& Buiter, Willem (2003). Corporate Governance in Developing, Transition and Emerging-Market Economies. Francia: OCDE Development Centre, Policy Brief 23. Disponible en: http://www.oecd. org/dev/poverty/28658158.pdf

Opler, Tim C. \& Titman, Sheridan (1994). Financial Distress and Corporate Performance. The Journal of Finance, 49 (3), 1015-1040. Organisation for Economic Co-operation and Development, OECD (1999). OECD Principles of Corporate Governance. Paris, OECD. Disponible en: http://www.oecd.org/ officialdocuments/publicdisplaydocumentp $\mathrm{df} / ? \mathrm{cote}=\mathrm{C} / \mathrm{MIN}(99) 6 \&$ docLanguage $=\mathrm{En}$

Organisation for Economic Cooperation and Development, OECD (2004). OECD Principles of Corporate Governance. Paris, OECD. Disponible en: https://www.oecd.org/corporate/ca/ 
corporategovernanceprinciples/31557724. pdf, doi:10.1787/9788485482726-es

Organisation for Economic Co-operation and Development, OECD (2015). G20/ OECD Principles of Corporate Governance. Paris, OECD. Disponible en: http://www. oecd.org/corporate/principles-corporategovernance.htm

Papineau, David (1979). Theory and Meaning. Oxford: Clarendon Press.

Pathan, Shams; Skully, Michael T. \& Wickramanayake, Jayasinghe (2008). Reforms in Thai Bank Governance: The Aftermath of the Asian Financial Crisis. International Review of Financial Analysis, 17 (2), 345-365. Disponible en: http://papers.ssrn.com/sol3/ papers.cfm?abstract_id=1097285

Pinheiro Neto Advogados (2000). Corporate Governance Assessment: Brazil. Mimeo, Paper presented at First Meeting of the Latin American Corporate Governance Roundtable OECD, Organisation for Economic Co-operation and Development. Disponible en: http://www.oecd.org/daf/ca/ corporategovernanceprinciples/1929992. pdf

Porta, Rafael la; López de Silanes, Florencio \& Shleifer, Andrei (1999). Corporate Ownership Around the World. The Journal of Finance, 54 (2), 471-517. Disponible en: http://onlinelibrary.wiley.com/ doi/10.1111/0022-1082.00115/pdf

Porta, Rafael la; López de Silanes, Florencio \& Shleifer, Andrei \& Vishny, Robert W. (1998). Law and Finance. The Journal of Political Economy, 106 (6), 1113-1155. Disponible en: http://faculty.som.yale.
edu/zhiwuchen/EmergingMarkets/ LawAndFinance.pdf

Porta, Rafael la; López de Silanes, Florencio \& Shleifer, Andrei \& Vishny, Robert W. (2002). Investor Protection and Corporate Valuation. The Journal of Finance, 57 (3), 1147-1170. Disponible en: http://scholar. harvard.edu/files/shleifer/files/valuation_ jofjune2002.pdf

Price, Richard A.; Román, Francisco J. \& Rountree, Brian R. (2006). Governance Reform, Share Concentration and Financial Reporting Transparency in Mexico. Disponible en: http://papers.ssrn.com/sol3/papers. cfm?abstract_id $=897811$

Rajan, Raghuram G. \& Zingales, Luigi (1998). Financial Dependence and Growth. American Economic Review, 88 (3), 559-586.

Ramdani, Dendi \& Witteloostuijn, Arjen van (2010). The Impact of Board Independence and CEO Duality on Firm Performance: A Quantile Regression Analysis for Indonesia, Malaysia, South Korea and Thailand. British Journal of Management, 21 (3), 607-627.

Rosenstein, Stuart \& Wyatt, Jeffrey G. (1990). Outside Directors, Board Independence, and Shareholder Wealth. Journal of Financial Economics, 26 (2), 175-191.

Ryan, Bob; Scapens, Robert W. \& Theobald, Michael (2004). Metodología de la investigación en finanzas y contabilidad. Barcelona: Ediciones Deusto.

Saito, Richard (2000). Differential Pricing of Equity Classes, Majority Control, and Corporate Governance: Evidence from the Brazilian Equity Market. Latin American Research Consortium, 
GOBIERNO CORPORATIVO Y DESEMPEÑo FINANCIERO / N. ESCOBAR, J. BENAVIDES, H. PERAFÁN / 253

LARC, mimeo. Disponible en:

https://www.oecd.org/corporate/ca/

corporategovernanceprinciples/1806633.

pdf

Shabbir, Amama (2008). To Comply or Not To

Comply: Evidence on Changes and Factors

Associated with the Changes in Compliance

with the UK Code of Corporate Governance.

Cranfield University, Cranfield School

of Management, Research Paper 5/08.

Disponible en: https://dspace.lib.cranfield. ac.uk/bitstream/1826/2482/1/RP5-08.pdf

Shabbir, Amama \& Padgett, Carol (2005).

The UK Code of Corporate Governance: Link between Compliance and Firm Performance. International Capital Market Association, ICMA Centre Finance Discussion Paper DP2005-17. Disponible en: http://www. icmacentre.ac.uk/pdf/discussion/DP200517.pdf

Shleifer, Andrei \& Vishny, Robert W. (1997). A Survey of Corporate Governance. The Journal of Finance, 52 (2), 737-783.

Silva-Colmenares, Julio (2004). El gran capital en Colombia: proyección al siglo XXI. Bogotá: Editorial Planeta.

Smith, Adam ([1776] 1994). La riqueza de las naciones. Madrid: Alianza.

Spamann, Holger (2008). 'Law and Finance' Revisited. Cambridge, Massachusetts, John M. Olin Center for Law, Economics, and Business Fellows' Discussion Paper Series, Discussion paper 12. Disponible en: http:// www.law.harvard.edu/programs/olin_ center/fellows_papers/pdf/Spamann_12.pdf Spamann, Holger (2010). The 'Antidirector Rights Index' Revisited. Review of Financial
Studies, 23 (2), 467-486. Disponible en: http://www.spamann.net/, doi:10.1093/rfs/ hhp067

Stulz, René M. (1988). Managerial Control of Voting Rights: Financing Policies and the Market for Corporate Control. Journal of Financial Economics, 20 (1-2), 25-54.

Sunder, Shyam (1997). Teoría de la contabilidad y el control. Bogotá: Universidad Nacional.

Tarziján, Jorge M. (2003). Revisando la teoría de la firma. Abante, 6 (2), 149-177. Disponible en: http://eacc10.puc.cl/files/ ABT/Contenidos/Vol-6-N2/3Tarzijan.pdf Tirole, Jean (2005). Corporate Governance. En The Theory of Corporate Finance, 15-73. Princeton, New Jersey: Princeton University Press.

Tosi, Henry L.; Brownlee, Amy L.; Silva, Paula \& Katz, Jeffrey P. (2003). An Empirical Exploration of Decision-making Under Agency Controls and Stewardship Structure. Journal of Management Studies, 40 (8), 2053-2071. doi:10.1046/j.14676486.2003.00411.x

Valle, Clemente del \& Carvajal, Mauricio (2005). Gobierno corporativo en Colombia: desarrollos y perspectivas. En Claves del gobierno corporativo, 69-82. Bogotá: Confederación Colombiana de Cámaras de Comercio, Confecámaras.

Vargas-Sánchez, Alfonso; García de Soto-Camacho, Elena \& Moreno-Domínguez, María Jesús (2003). La teoría de la agencia versus la teoría del servidor: una aplicación a las sociedades cooperativas agrarias del país de Gales (Reino Unido). En José Manuel Barreiro-Fernández, José Alberto Diez de 
Castro, Begoña Barreiro-Fernández, Emilio Ruzo-Sanmartín \& Fernando Losada-Pérez (coords.). Gestión científica empresarial: temas de investigación actuales, 19-32. A Coruña: NetBiblo.

Vélez-Montes, Diego; Holguín-Lagos, Harry; De La Hoz-Pinzón, Gerardo Augusto; Durán-Bobadilla, Yasmín \& Gutiérrez-Ayala, Irma (2008). Estado del arte de la empresa familiar y el problema de la sucesión. En Dinámica de la empresa familiar pyme. Estudio Exploratorio en Colombia, 5-18. Bogotá: Fundes Internacional. Disponible en:

Villalonga, Belén \& McGahan, Anita M. (2005). The Choice Among Acquisitions, Alliances, and Divestitures. Strategic Management Journal, 26 (13), 1183-1208.

Wasserman, Noam (2006). Stewards, Agents, and the Founder Discount: Executives Compensation in New Ventures. Academy of Management Journal, 49 (5), 960-976.

Wooldridge, Jeffrey M. (2010). Econometric Analysis of Cross Section and Panel Data. Cambridge, Massachusetts, London, England: MIT Press.

Yermack, David (1996). Higher Market

Valuation for Firms with a Small Board of
Directors. Journal of Financial Economics, 40, 185-211. Disponible en: http://people.stern. nyu.edu/eofek/PhD/papers/Y_Higher_JFE. pdf

Zheka, Vitaliy (2006). Corporate Governance and Firm Performance in Ukraine. Centre for Economic Reform and Transformation, CERT Discussion Papers 0605, Heriot Watt University. Disponible en: http://www2. hw.ac.uk/sml/downloads/cert/wpa/2006/ dp0605.pdf

- Fecha de recepción: 02 de septiembre de 2015

- Fecha de aceptación: 30 de mayo de 2016

- Disponible en línea: 30 de junio de 2016

\section{Para citar este artículo}

Escobar-Váquiro, Natalia; Benavides-Franco, Julián \& Perafán-Peña, Héctor Fabio (2016). Gobierno corporativo y desempeño financiero: conceptos teóricos y evidencia empírica. Cuadernos de Contabilidad, 17(43), 203-254. http://dx.doi. org/10.11144/Javeriana.cc17-43.gcdf 